This article has been scanned by iThenticat No plagiarism detected

Volume 3, Issue 5, October 2021

p. 358-370

\title{
CONTEMPORARY MAKE_UP TECHNIQUES AND AESTHETIC ADDITIONS TO THE DRAMATIC CHARACTER IN CHILD THEATER
}

http://dx.doi.org/10.47832/2757-5403.5-3.31

\section{Thikra ABDULSAHIB 1}

\begin{abstract}
:
The art of makeup is one of the main elements of the integrative system of the theatrical performance at times and of the drama directed towards children in their school theater at other times. This is because makeup has an effective impact in shaping the personality and appearance of the actors in the drama. This includes the practice of drawing, improving or changing the actor's face as well as shaping his body, hair and his entire form during dramatic practices, masquerade parties and some festival occasions, such as the Halloween Festival in America, by using materials and products specially manufactured for the world of makeup and cosmetics. Makeup has been used since Greek times after the emergence of the theater in its new dithyrambic form in the time (Aeschylus and Euripides) and after the actors abandoned the theatrical mask which enabled one actor to play several roles in the educational drama. After the industrial revolution in the Renaissance, makeup turned into a world of creativity and beauty by using its manufactured products and bright colors for drawing and shaping alongside stage candles and lit lanterns in that era. This is until it entered the early children theater to become one of the necessities of child-oriented work to increase tension and suspense and to convey meaning through the embodiment of characters in the dramatic work, regardless of their type (human or animal, inanimate or scientific fiction and fantasy). Ever since the beginning of the nineteenth century and until the present day, the makeup technology has gone through the development of manufacturing and shaping of its plastic materials and the method of work until the makeup professionals mastered creating characters and shapes that are difficult for the non-experienced to create.
\end{abstract}

\footnotetext{
${ }^{1}$ Dr. , International Center for Research and Studies of Traditional Music, Iraq, thikraabd05@gmail.com, https://orcid.org/0000-0003-2370-5428
}

Copyright (C) Published by IJHER Journal, www.ijherjournal.com Rimar Academy, Fatih, Istanbul, 34093 Turkey

All rights reserved 
Therefore, the researcher has found that it is important to study the makeup techniques, their aesthetics, and the complementary additions to the theatrical character's body performed in all its environmental, psychological, social and health details, as well as the level of awareness and perception through color, mass, line, composition, rhythm, and other complements such as wigs and beards. That is because it attracts the child and makes him more interactive and communicative with the total display system in which all the kinetic, color, light and sound scenographic elements combine, achieving integration in the spectacle of the artwork and its aesthetics as well as achieving both its intellectual and artistic goals.

Because of the importance of contemporary makeup techniques and aesthetic additions in our time and their impact on the dramatic personality and on the culture and taste of the child in general, the researcher decided to delve into and study the subject with the aim of reaching a package of recommendations that enrich her research paper.

Key words: Child Theater, Make_Up Techniques, Dramatıc Character.

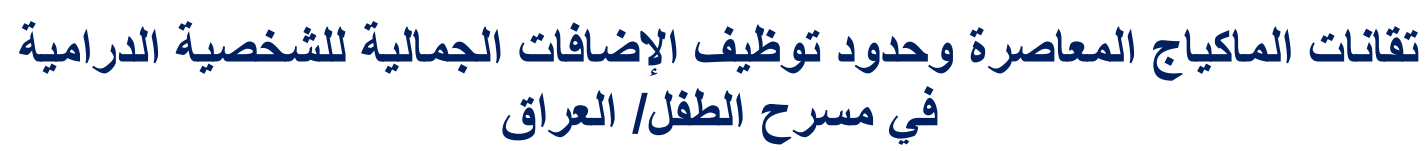

ذكرى عبد الصاحب عبادي 2

\begin{tabular}{|c|}
\hline 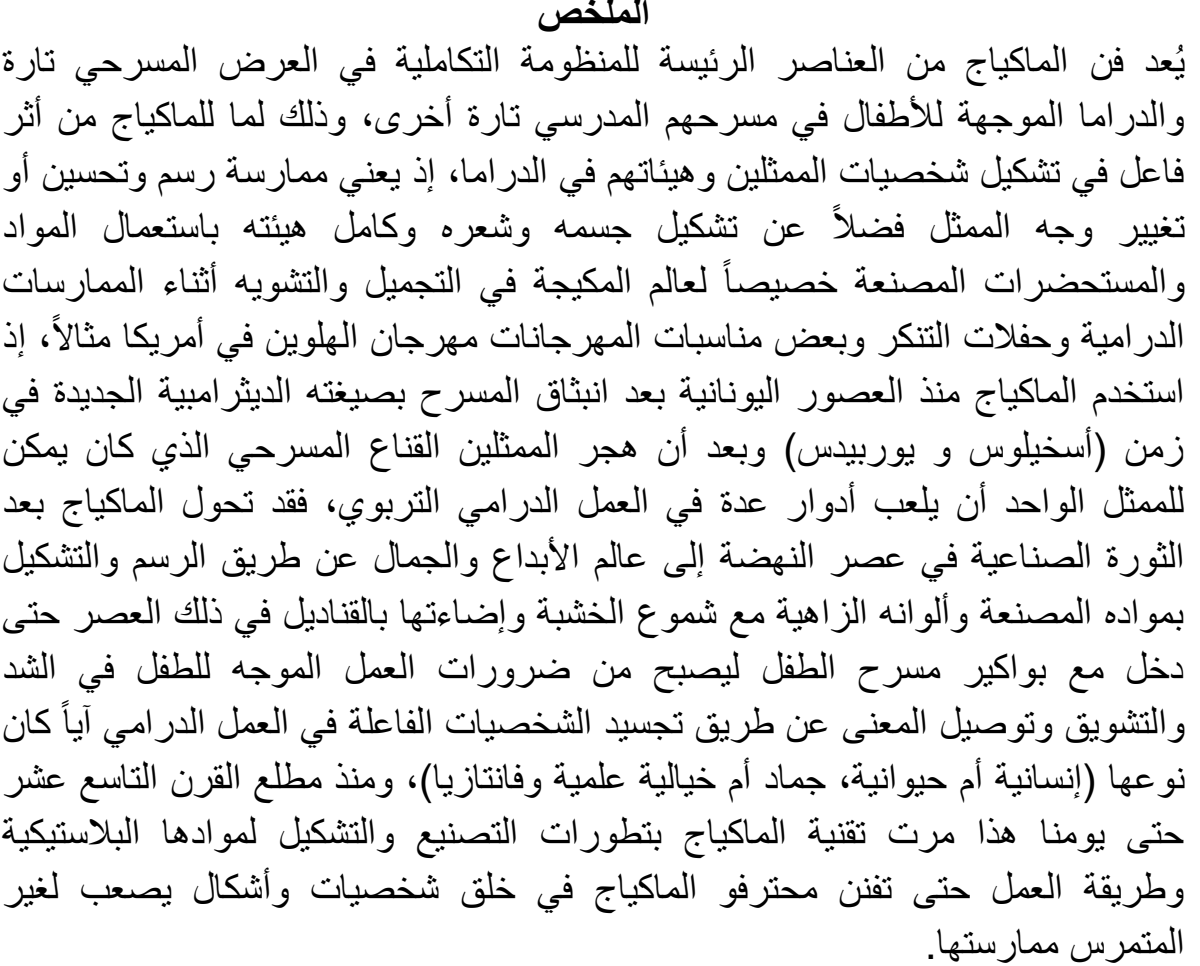 \\
\hline
\end{tabular}

thikraabd05@gmail.com بد.2، المركز الدولي للبحوث و الدراسات الموسيقية الثقليدية، العراق، 


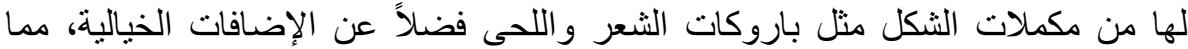

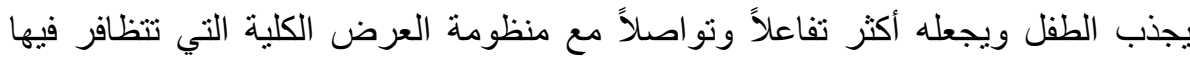

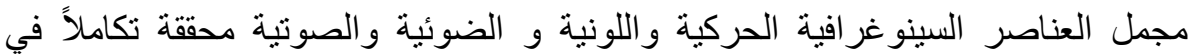
مشهدية العمل الفني وجمالياته وتحقيق أهدافه الفكرية و الفنية معاً.

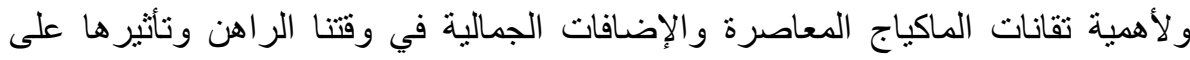

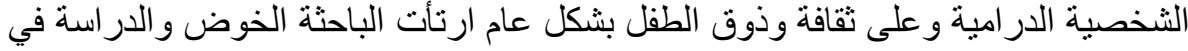

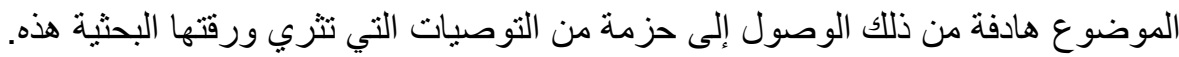

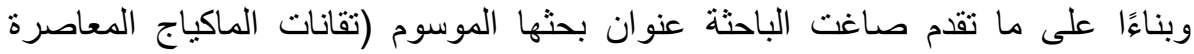

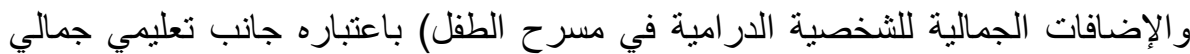

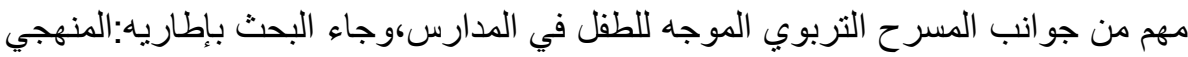

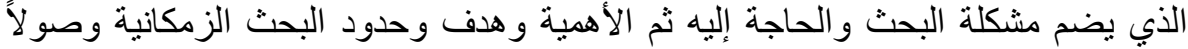

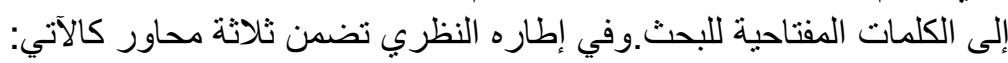

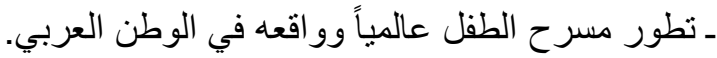

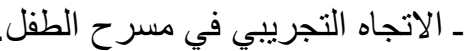

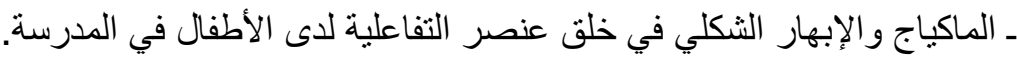

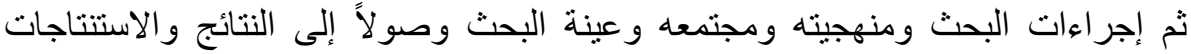

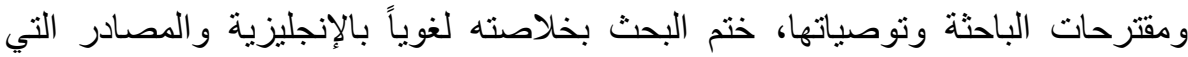
اعتمدتها الباحثة للوصول إلى البى النتائج. الكلمات المفتاحية: مسرح الطفل، لقاناتات الماكياج، الثخصية الدرامية.

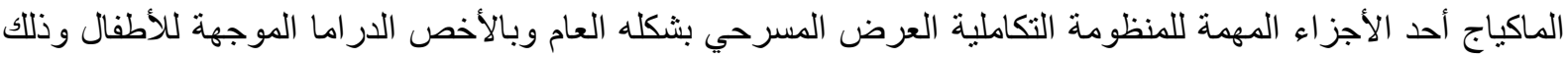

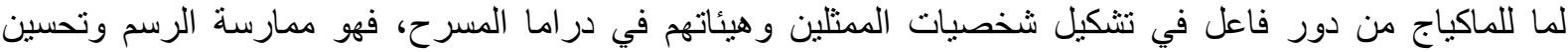

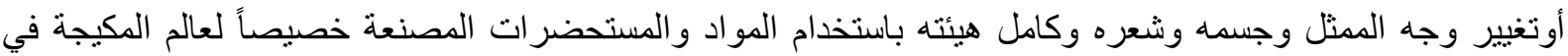

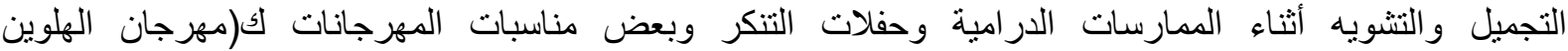

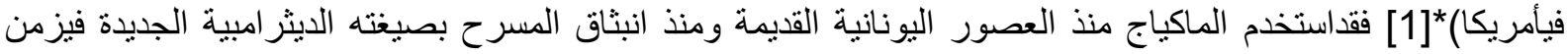

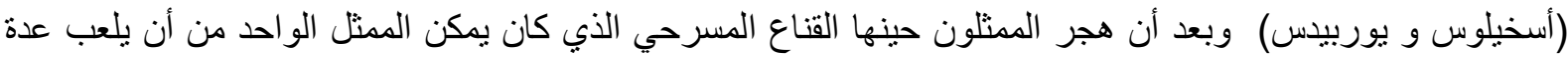

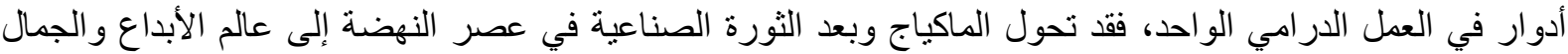

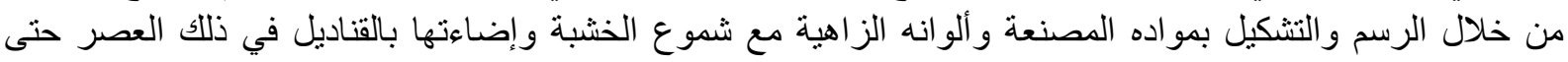
دخل مع بو اكير مسرح الطفل ليصبح من ضروريات العمل الموجه للطفل في الجذب و الإبهار و التشويق و إثراء المعاء المعنى

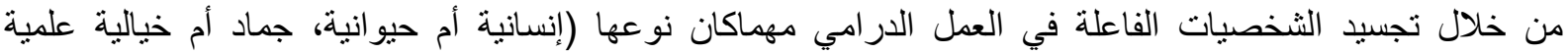
وفانتازيا) ومنذ القرن التاسع عشر حتى يومنا هذا مرت تقنية الماكياج بتطورات تقانية وجمالية في التصنيع والاستخدام

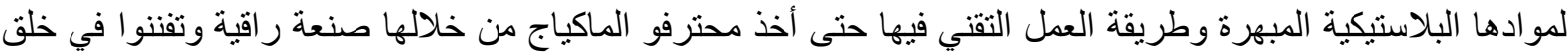
شخصيات وأنشكال يصعب علي غير المتمرس فئها صنع مثل تللك الأشكال.

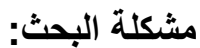

كان لابد من الوصول إلى ما يعزز أهمية البحث هو طرح إثكالية البحث فيه للوصول إلى سبل تطبيق مفرداته والإفادة

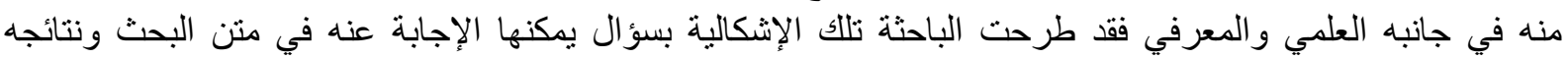
و واستتناجاته فجاءت المشكلة بصيغة التساؤل الآتي: هل لتقنيات ماكياج المسرح الحديثة من دور في ترسيخ القيم التربوية

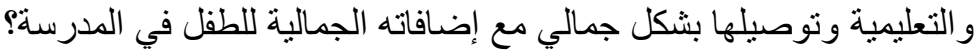

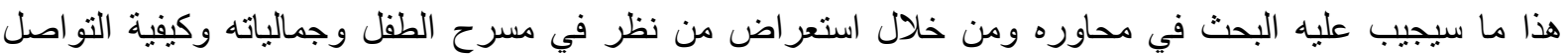
و الاتصال مع أفكار الطفل من خلال عروض مسرحهم الجميل ومن خلال ما سيتوصل فيل إليه من نتائج. 


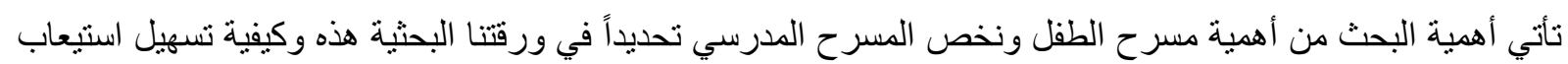

المناهج المدرسية بطرق جمالية محفزة و ألو ان و أثنكال مبهرة للأطفال الصغار لكي لا تتخم أفكار هم بالتلقين و الحفظ.

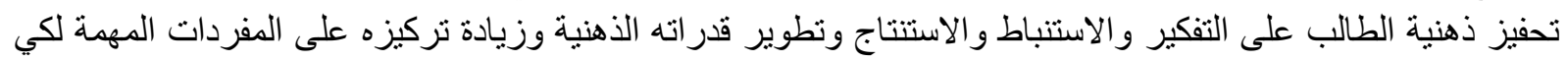
لا يصبح الأطفال مرددين لا مفكرين. الطفل يميل إلى الحركة وفي الحركة تأثير إيجابي على صحته سواء على الإنى الجسد أو على نشاطه الذهني وتفكيره، ولها

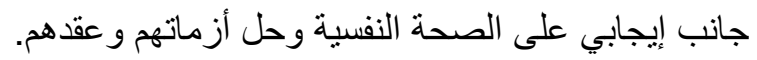
كما ويعزز قدر ات أطفالنا الصغار وطرق تفكير هم في الابتعاد عن التلقين.

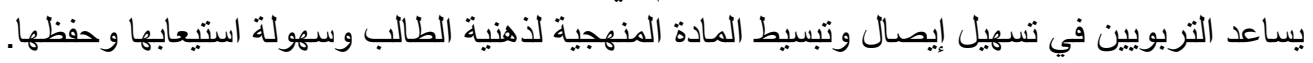

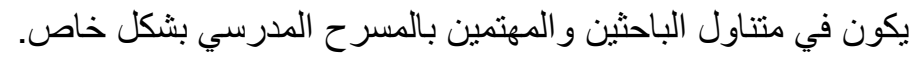
يفيد المؤسسات التربوية و الفنية في ترصين عملية المسرحة و إعادة النظر بالمناهج الدراسية ولجميع المر احل الدراسية.

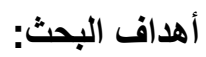

يهدف البحث إلى: الكثف عن تقانات الماكياج المعاصرة ومهارات اشتغال الإضافات الجمالية على الثخصية الدرامية في

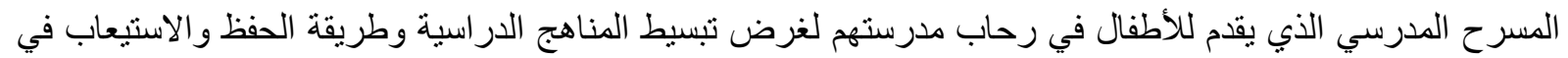

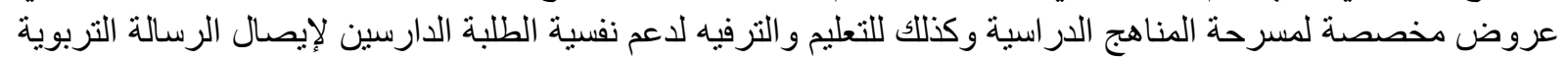
بشكل مؤثر وسليم.

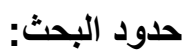
الموضو عية: الأعمال المسرحية التعليمية المدرسية.

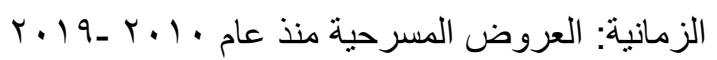
المكانية: العروض المقدمة على المسار ح المحلية لجهات مختلفة. منهج البحث: اتخذت الباحثة المنهج الوصفي التحليلي أسلوباً لبحثها.

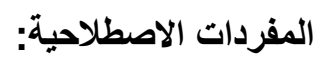
التقنيات: و هي جمع كلمة تقنية وتعرف على أنها جاءت من الكلمة الإنجليزية (Technology) مشنقة من (Techno)

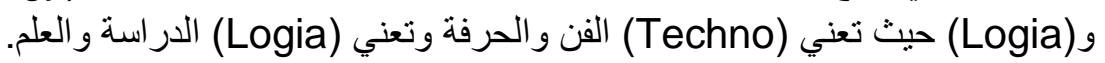

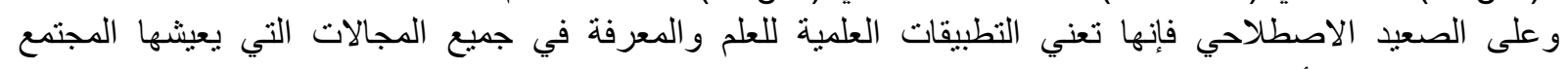

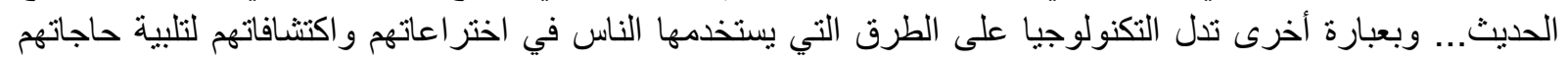

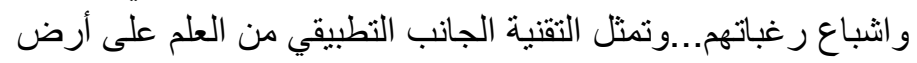

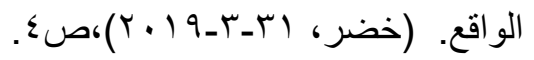

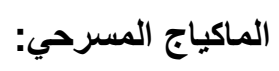

عرفه (سيرج سترنكوفسكي) هو فن تحويل مظهر الممثل 1. 1 لغرض خلق التشبيهات

2. على وفق المحتوى الذي اعتمده مؤلف المسرحية 3. على وفق الأسلوب الاخر اجي. 4. كلى وفق وانظمة المسر ح آو الثناشة.

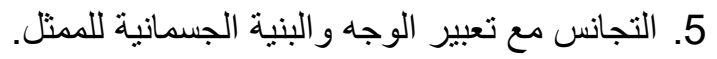

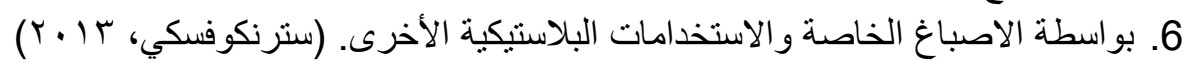




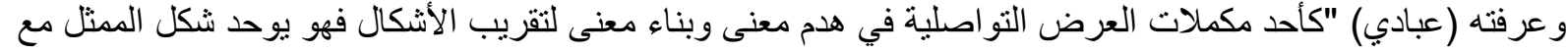

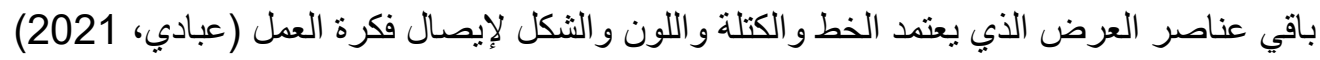

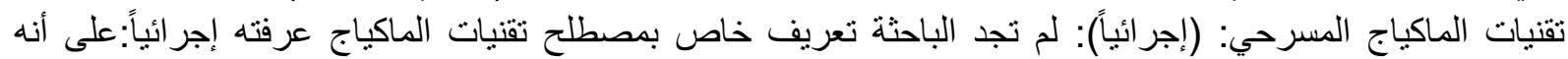

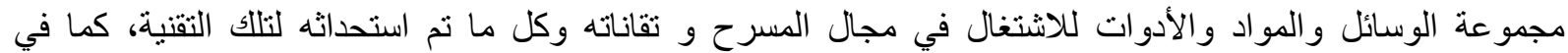

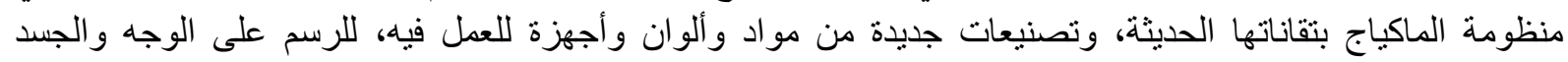
وتوضيح الملامح والتزويق ولبس الباروكات ووضع اللحى والثعور المستعارة، وحتى استعمال الأقتعة التي تخدم العملية

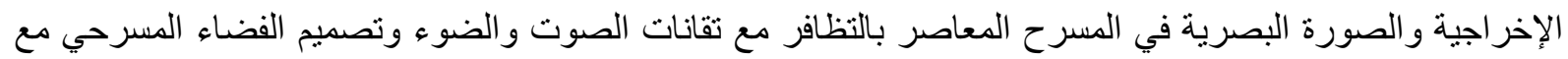

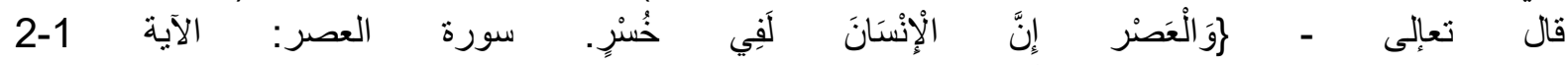

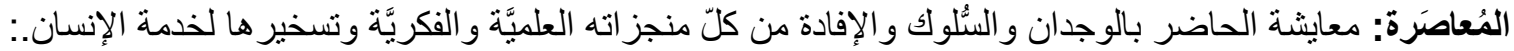

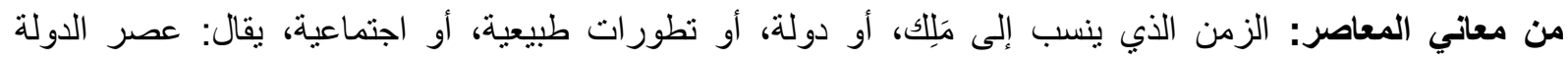

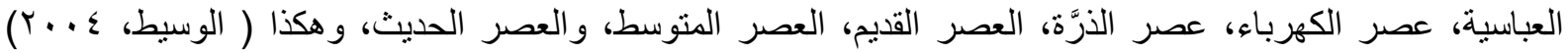

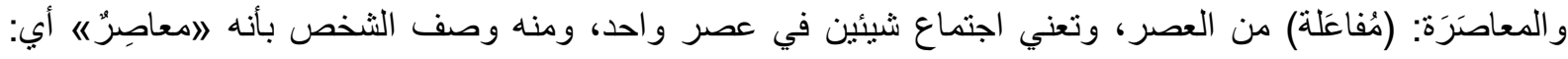

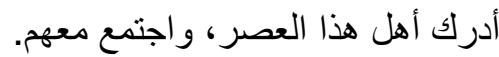
أما 》المعاصِرة) بكسر الصاد- المقصود بها الكائنة في هذا العصر الذي نعيش فيه، فالنوازل المعاصِر هي التي حصلت

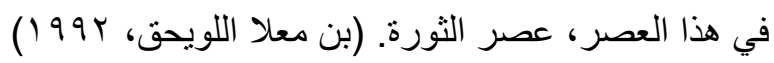
المعاصر إصطلاحاً: كل ما يحدث في الوقت الحاضر والذي ينتمي إلى أقرب فترة تأريخية بسمى المعاصر . صفته صفة فئة

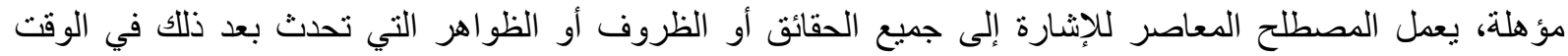

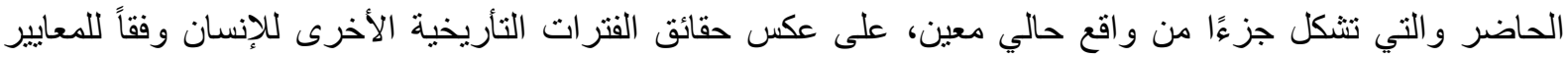

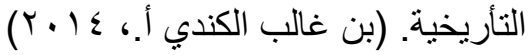

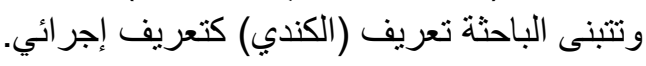

الإضافات الجمالية: لم تجد الباحثة تعريفا صريحاً بسلط الضوء على تعريف الإضافات الجمالية بشكل علمي فقد صاغت تعريفها الإجر ائي كما يأتي: (هي العناصر التي يتشكل منها الفياءئ الفياء المسرحي وتكوين التشكلات البصرية والسمعية والحركية المصاحبة لديناميكية

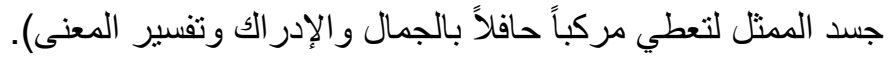

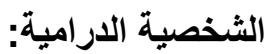

الشخصية -

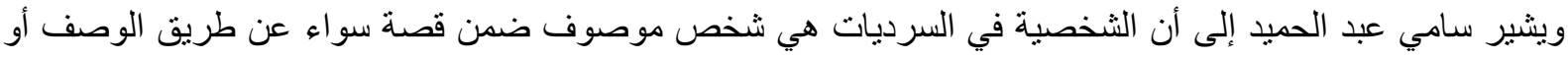

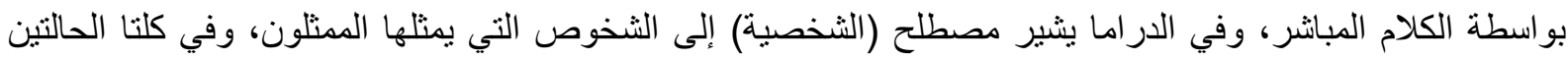
ليس ضرورياً أن تكون الثخصبات كائنات بشرية بل بمكن أن تكون وسائط حساسة كالآلهة و الحيو انات ومخلو قات التهات غريبة

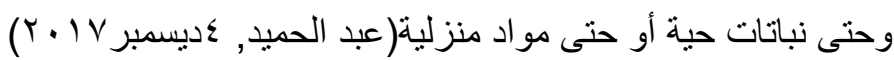

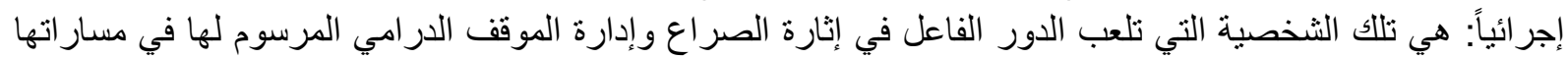
الدر اماتيكية حنى نهاية العمل و التي تثير جدلاً من حولها. 
عرفه (وارد) هو مسرح ملتزم بتقديم أفكار جديدة، وإخر اج شيق لجمهور من الصغار وتعريفهم بألوان مختلفة من الفن.

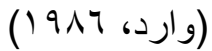
وعرفته (فيو لا) هو "المسرح الذي يكتب له مؤلفون مسرحيون ويقدم عروضه ممنلون حقيقيون لجمهور الأطفال، وقد

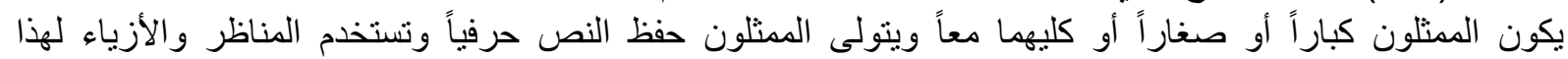
الغرض. (viola, 1974)

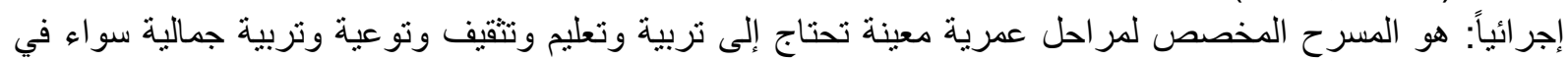
توظيف المناهج الدراسية التعليمية أو للترفيه و إكساب الخبرات و المهار ات بوات بواسطة المسرح الموجه لأطفال متلقين أو أو

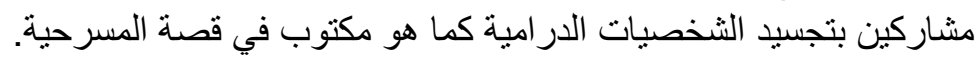

\section{المبحث الأول: تطور مسرح الطقل والمسرح المدرسي عالمياً وواقعه في الوطن العربي.}

تتطور الحياة بتر اكم الأزمان وتر اكم الخبرات والمنتج الإنساني في كل جوانبه، يأتي هذا التطور بانفتاح ذهنية الإنسان

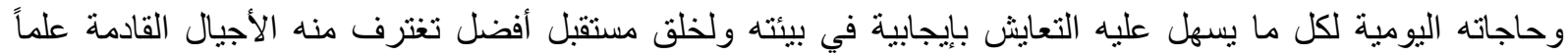

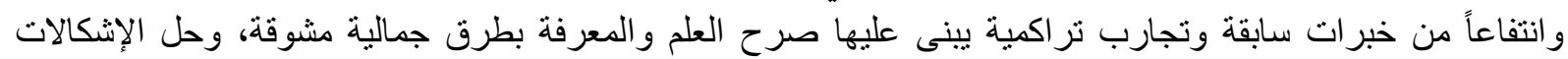

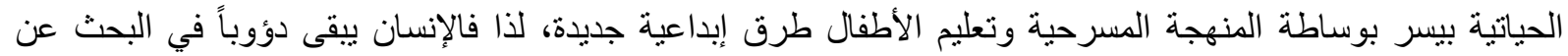

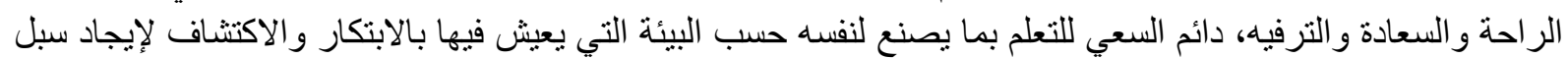

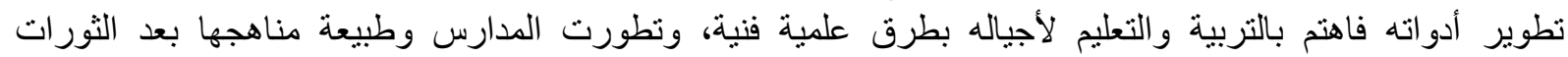

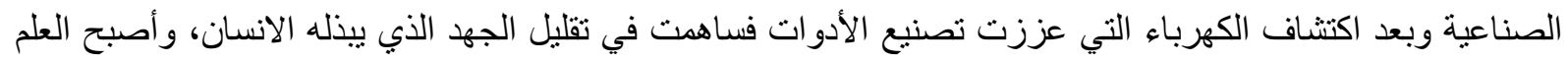

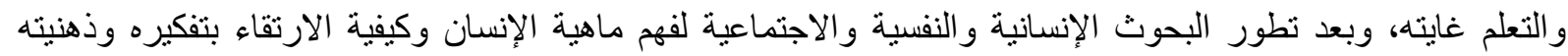

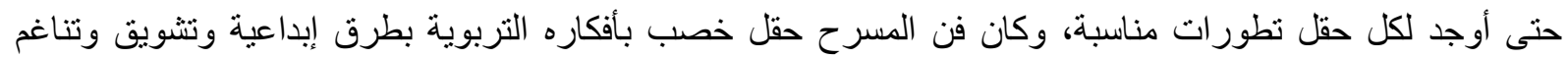

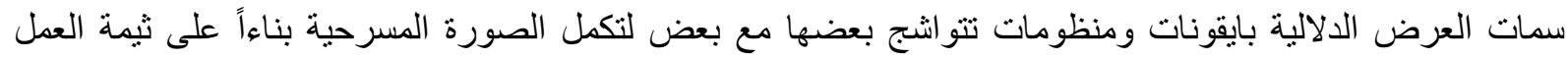

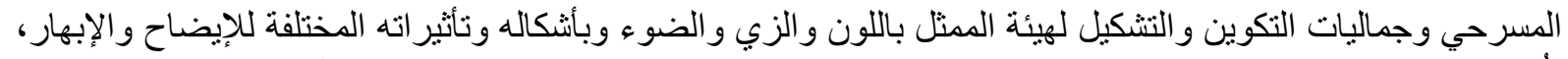

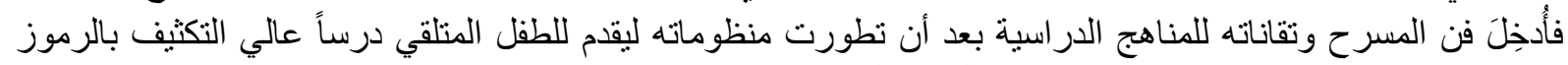

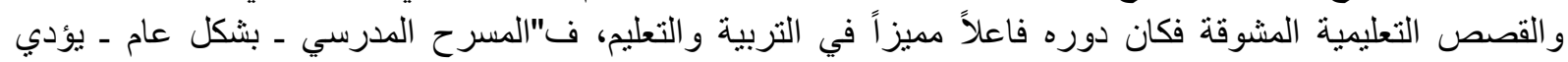

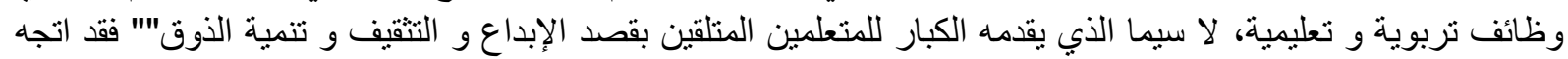

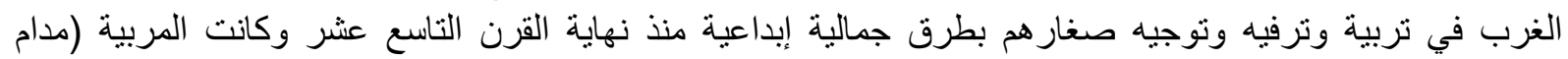

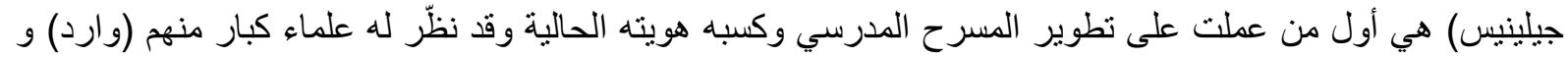

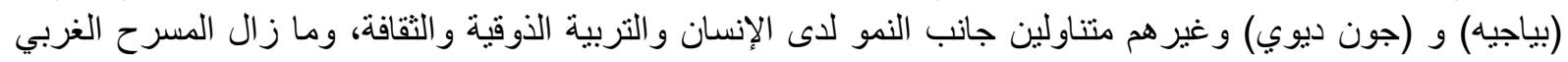

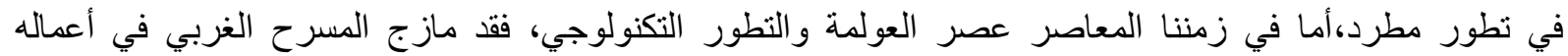

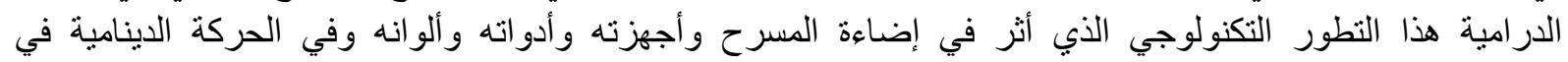

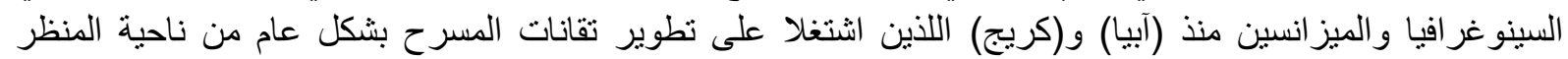

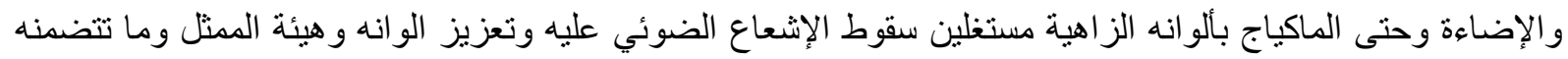

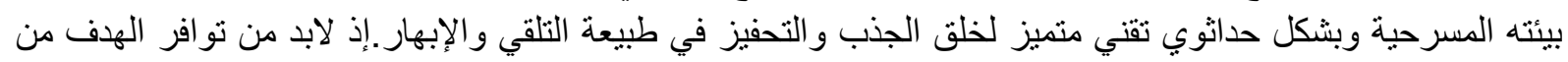

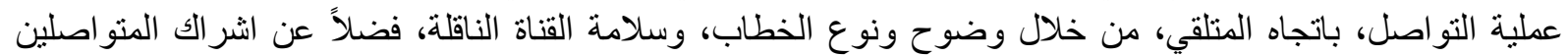

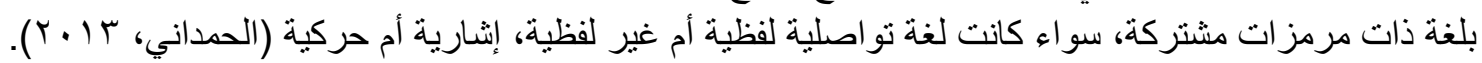

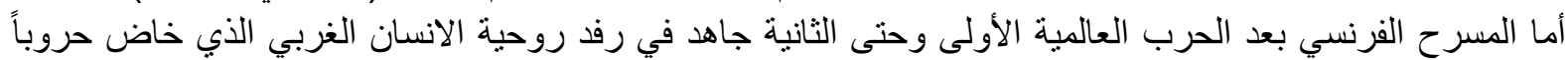

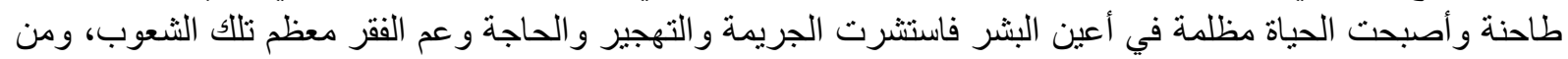

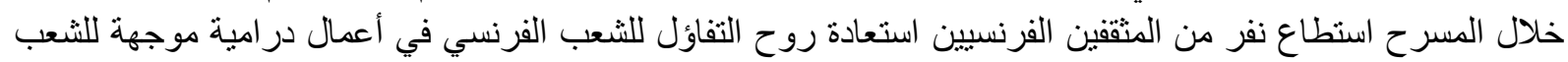

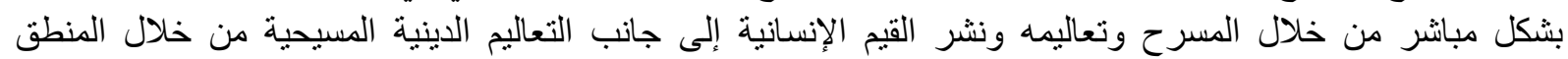

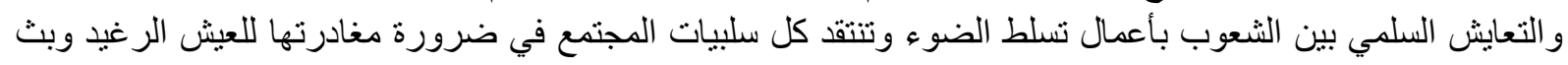

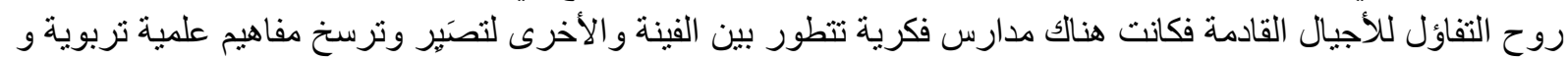

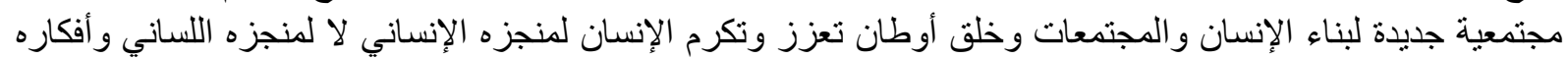

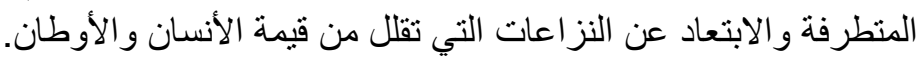




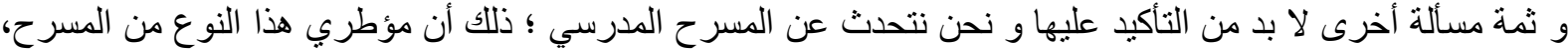

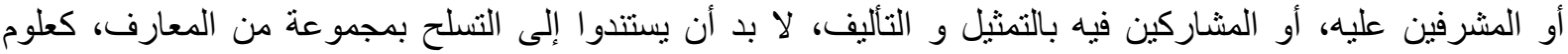

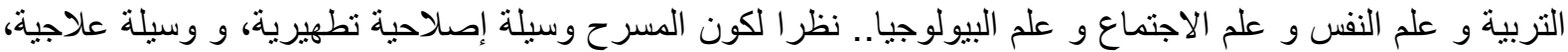
و وسيلة جمالية إبداعية، و وسيلة تلقين و نقل المعرفة و المهارة، كما أنه وسيلة إثباع حاجات الطفل ليتكيف مع الذات و النيات

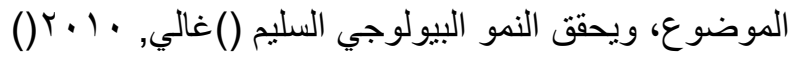

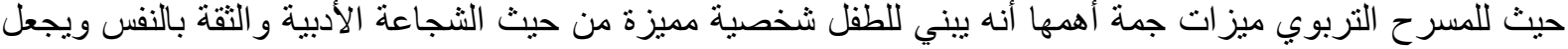

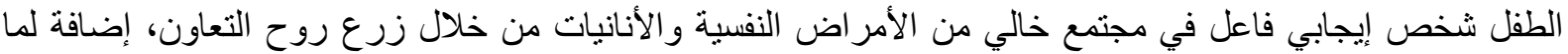

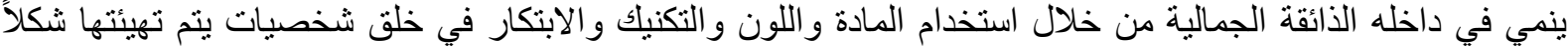

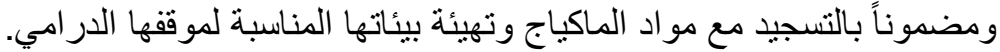

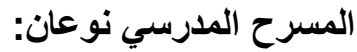

يرنكز النوع الأول منه على أساس اللعب الإيهامي أو التخيلي. و يعتبر هذا اللعب الأساس النفسي الذي يعبر من خلاله المتعلمون عن ذو اتهم و حاجاتهم النفسية و الاجنماعية. أما النوع الثاني منه أي الموجه يقدمه المتعلمون بنوجيه من المدرس و هو يجسد حوارات ومعلومات الدرس المنهجي.

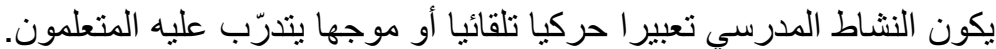

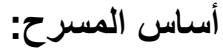

المسرح التربوي التعليمي التعلمي التلقائي المسرح التربوي التعليمي التعلمي الموجه من طرف المدرس، أو من يقوم مقامه كأن مسرحة أحداث، أو مسرحة نصا، أو مسرحة وضعيات تعليمية المسرح التربوي التعليمي الذي يقدمه الكبار

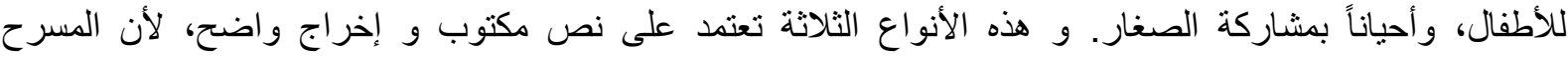

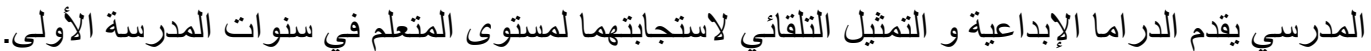

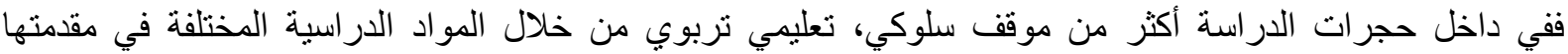

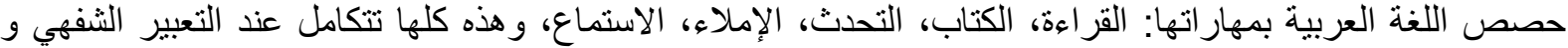

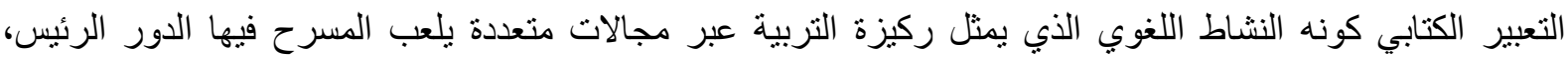

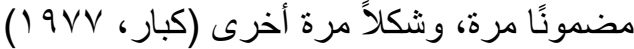
فالطفل هو المستهدف في العملية التربوية وحسب المقولة "علموهم صغار اً ليغدو ا كبار آ، أو التعلم في الصغر كالنقش على الصى الحجر" إذ أن ثقافة الطفل تشكل منعطفاً كبير اً في تقام الثعوب في تقديم برامج هادفة بعيداً عن ايديولوجيات السياسة و

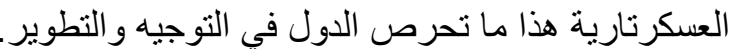

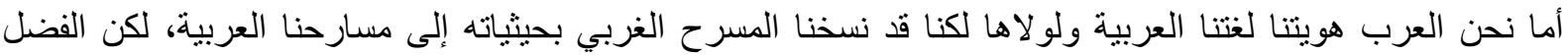

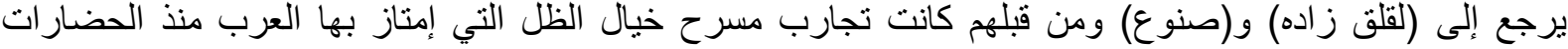
القديمة وبداية الدولة الإسلامية والتعلم في كتاتيب التدين التي حافظت على كتابنا القرآن الحنيف ولغته العربية من الضياع، فكانت بحق تجارب يشار إليها بالبنان في نقل بعض الإن الثقافات وصياغتها بشكل يتو افق مع طبيعة لغتنا ومجتمعنا الثرقي الذي يختلف فكرياً وسيسيولوجياً عن المجتمعات الغربية، فكانت هنالك نهضة عربية ما بعد النهضة الغربية النية التي

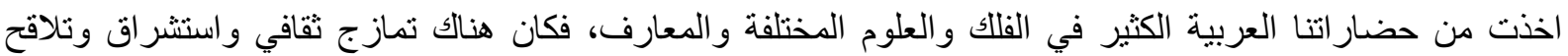

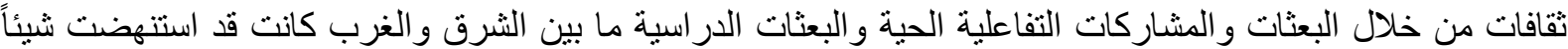

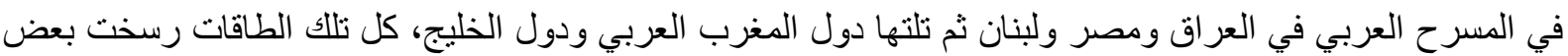
المفاهيم التربوية الصحيحة من خلال المسرح الو اقعي و التجريبي الذي أفرز طاقات وشخصيات إلى إبداعية منميزة في الوطن

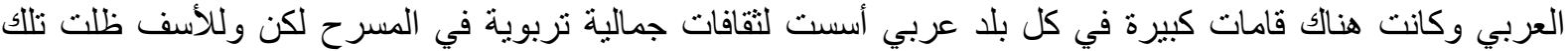

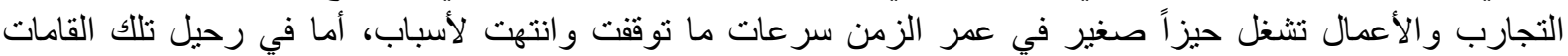

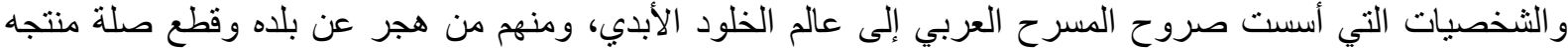

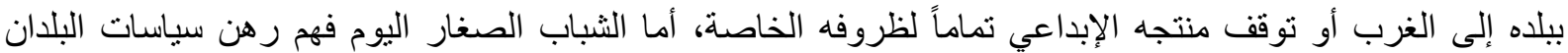

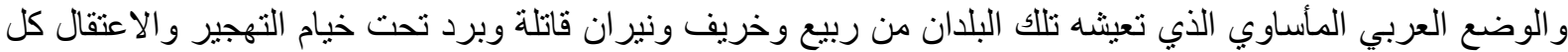

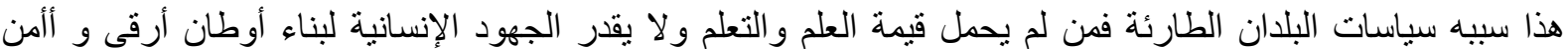

ليتعافى المسرح ويتعافى معه التعليم بشكل العام و الثقافة المجنمعية أجمع. 
المبحث الثاني: الإتجاه التجريبي في مسرح الطفل.

إن للطليعية والتجريب في حياتتا أهية كبيرة من أجل تطوير المناهج و الخروج عن المدارس الكلاسيكية والواقعية

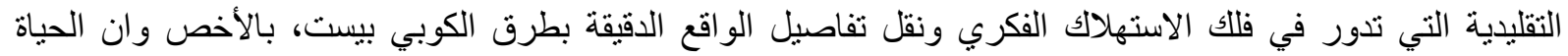

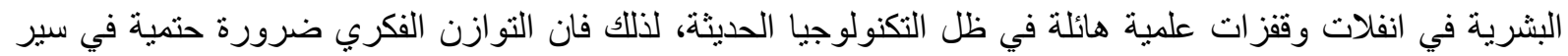

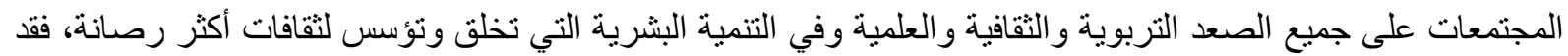

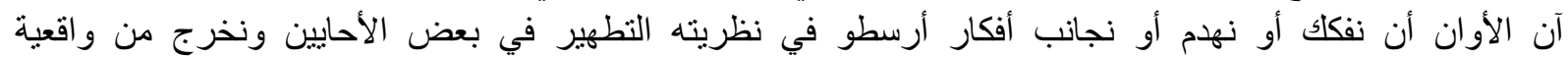

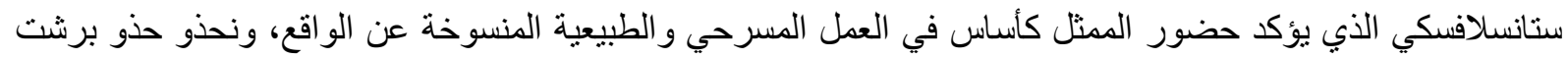

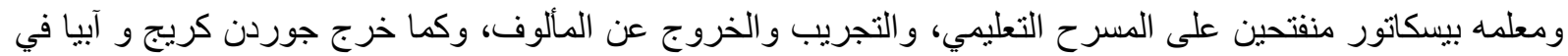

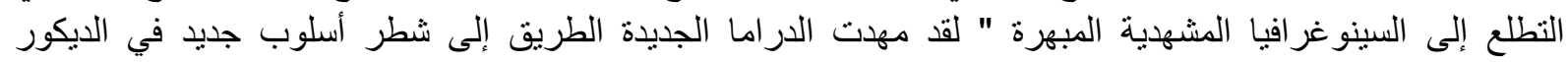

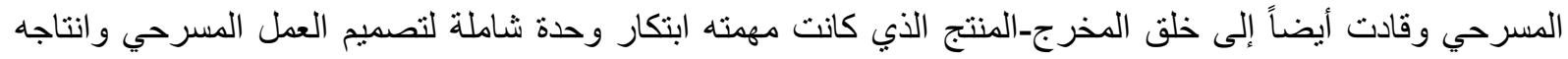

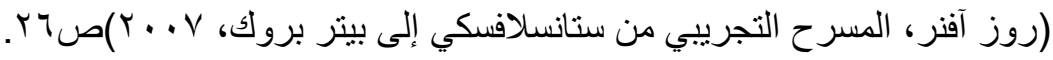

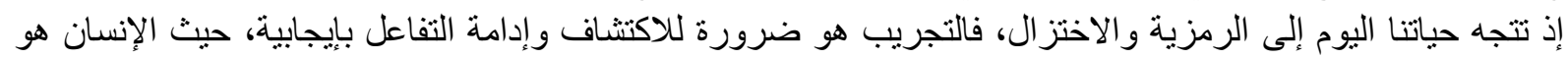

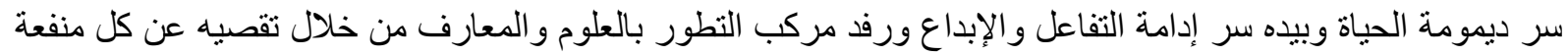

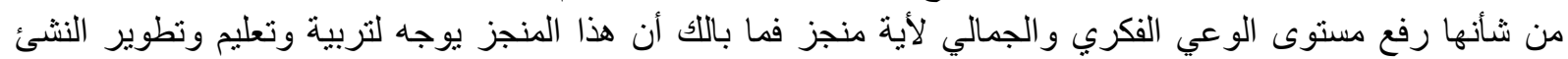

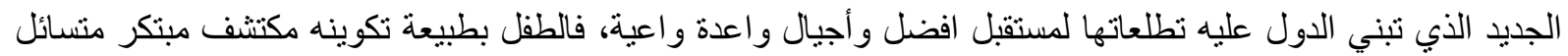

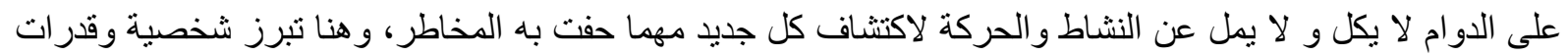

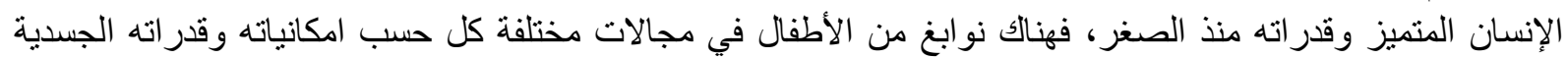

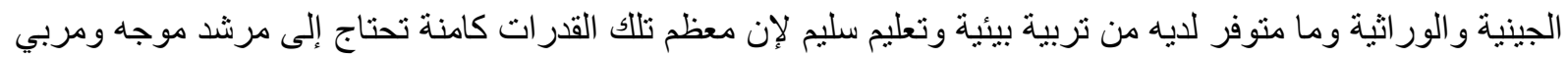

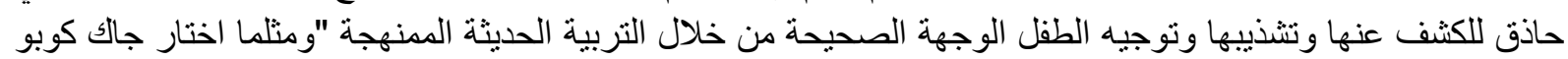

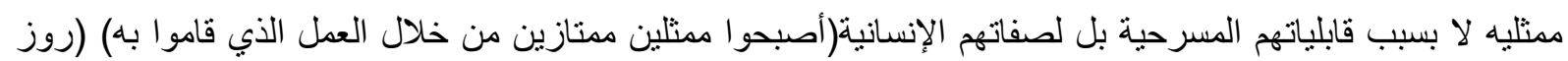

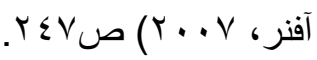
تللك المنهجية بمكننا رسمها وتنفيذها من خلال المسرح المليء بالتجارب و العبر و الثقافات و الرموز و الإشارات الدالالية،

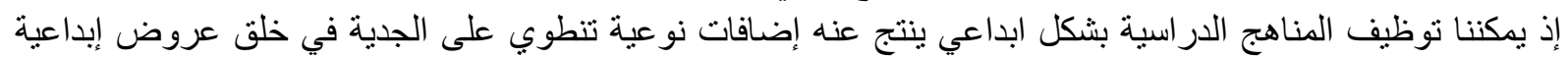

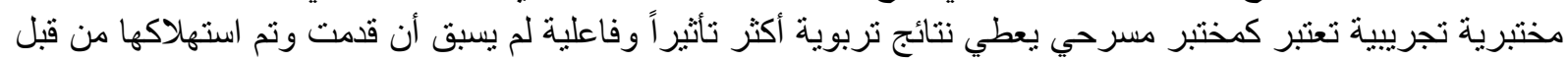

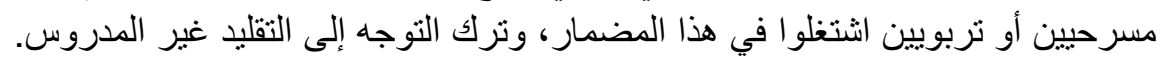

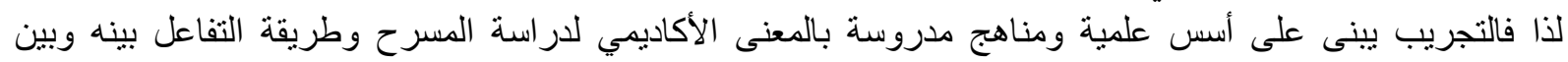
الجمهور وترصين الدلالات الخطابية المرئية و المسمو عة على حد سو اء لأجل الإثراء المعرفي والجئ الجمالي.

\section{المبحث الثالث: الماكياج والإبهار الثكلي في خلق عنصر التفاعلية لاى الأطفال في المدرسة.}

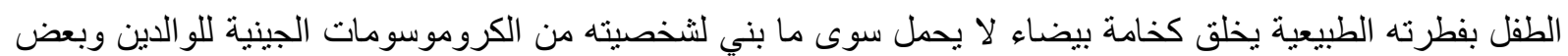

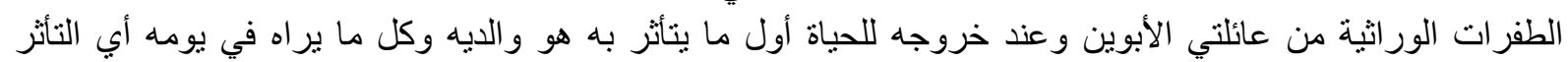

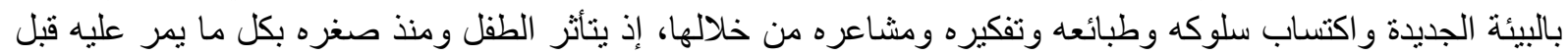

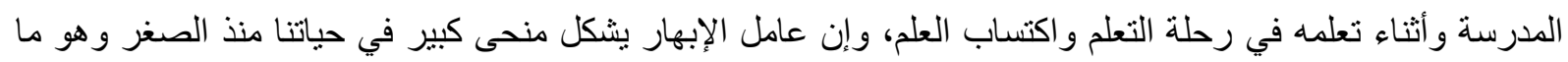

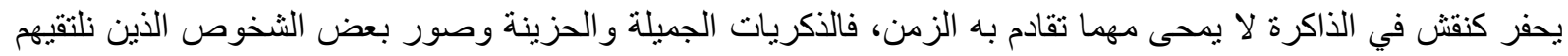

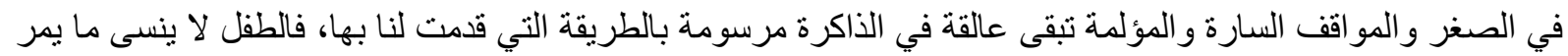

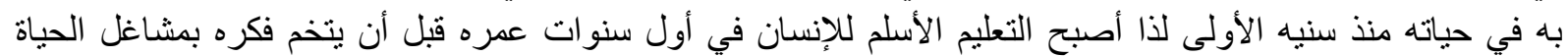

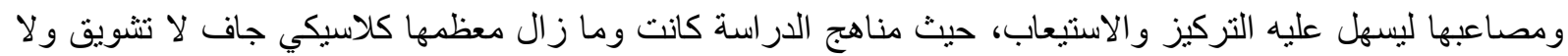

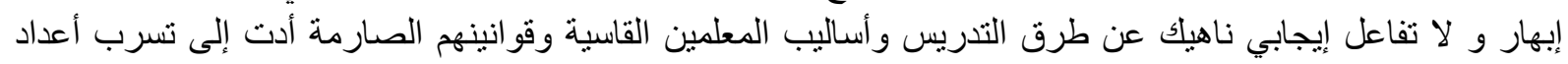

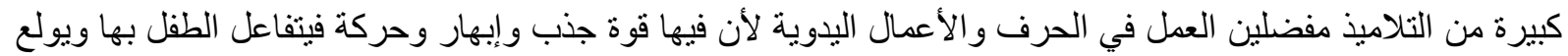

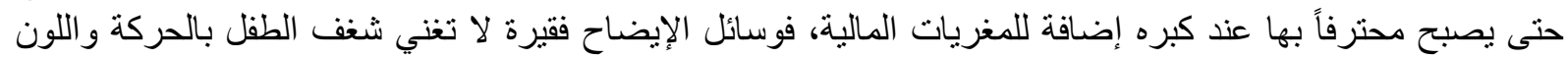

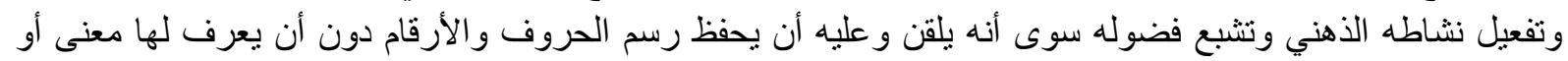

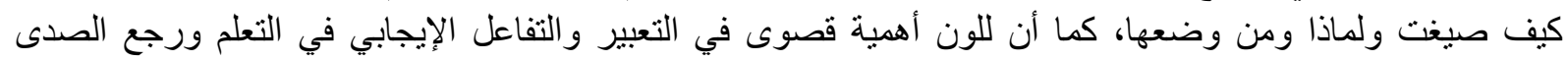

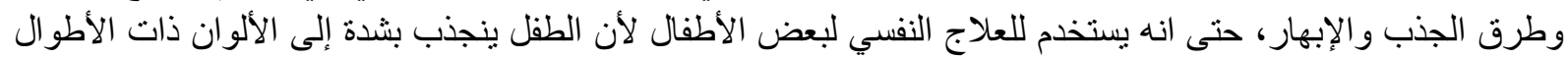




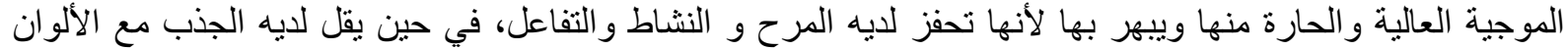

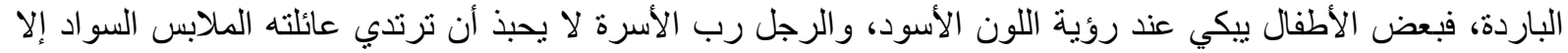

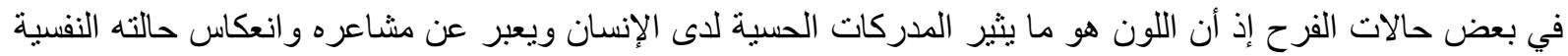

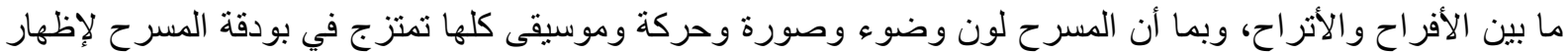

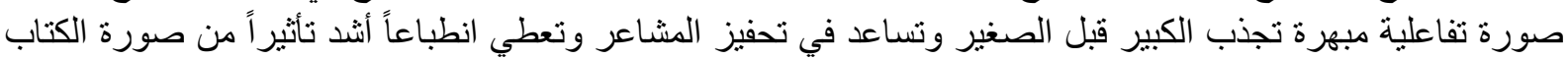

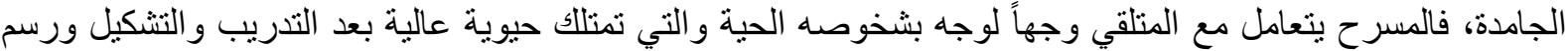

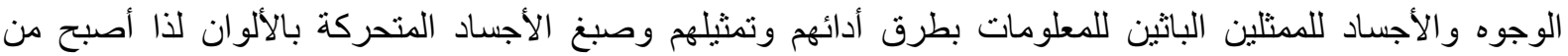

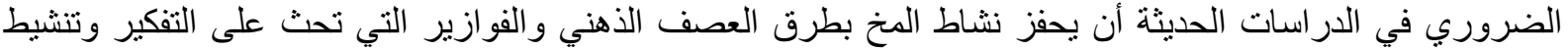

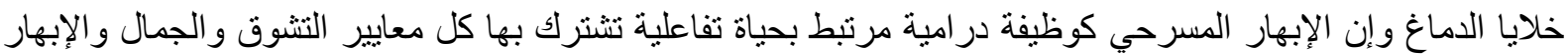

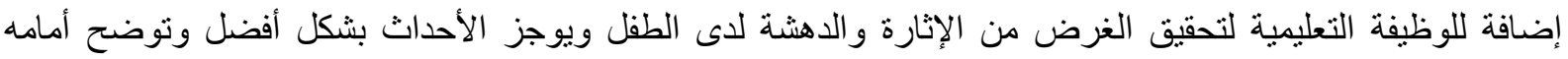

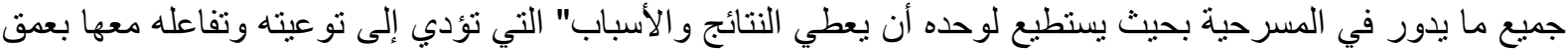

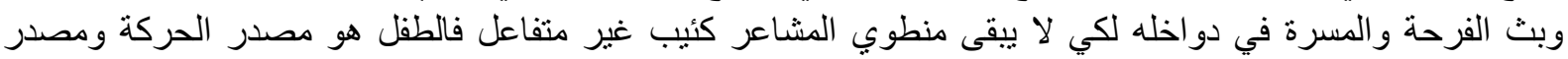
الحيوية و أساس النربية والتعلم.

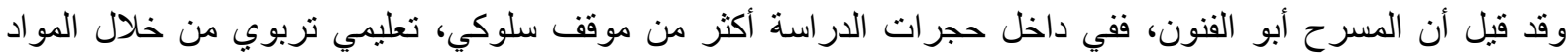

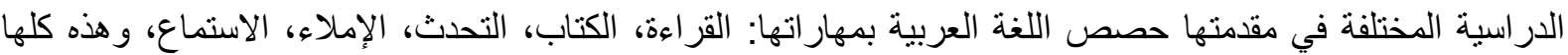

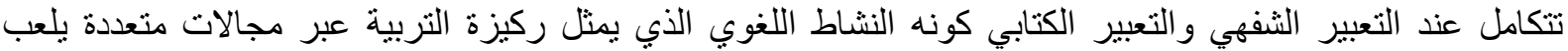

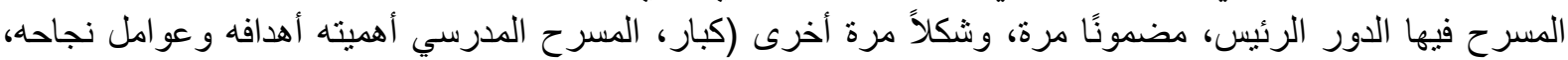

$(r+1 \mathrm{~V}$

فللثكل في المسرح التربوي ضرورة من أجل شد انتباه الصغار لما يقدم لهم من معلومات تربوية ومناهج تعليمية، كما

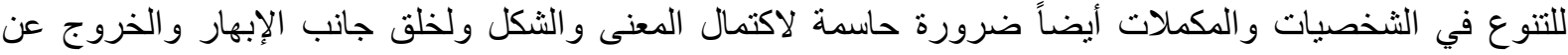
الرتابة إلى المتعة المنشودة.

التنوع في شخصيات مسرح الطقل:

التنوع في ما يقدم للطفل من شخوص مختلفة متجانسة وحسب قصة العمل الدرامي و المنهج المدرسي المحدد لكل فئة

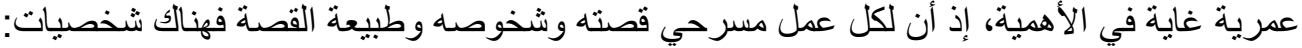

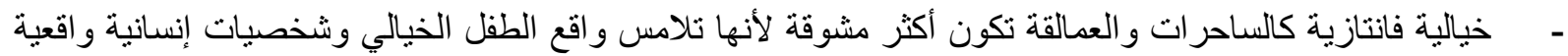
تمثل الأشخاص الاعتياديين و الثخصيات التأريخية والأبطال.

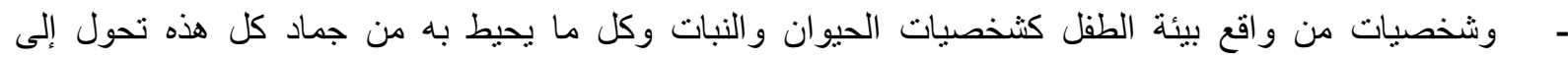

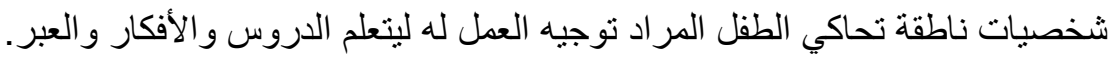

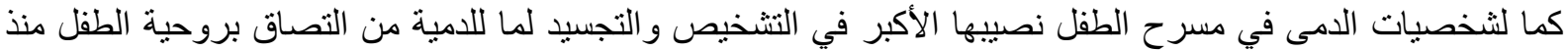

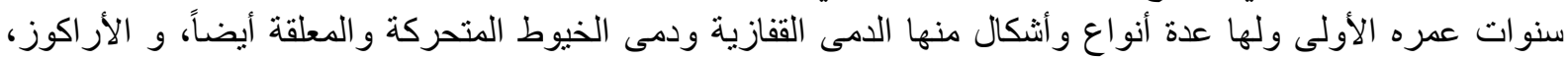

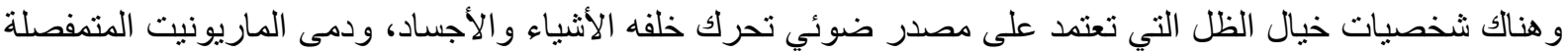

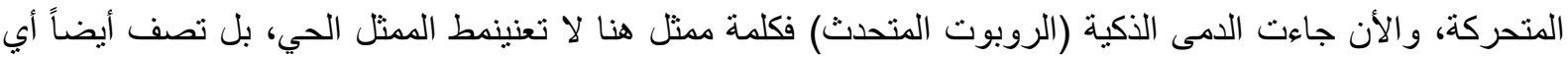

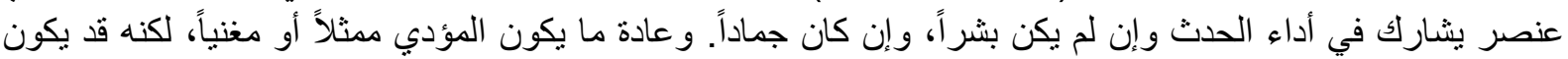

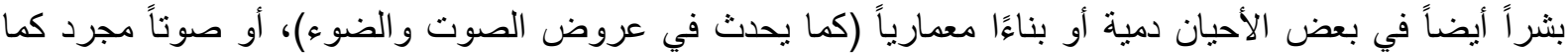

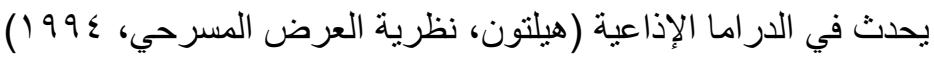
حيث الطفل ينتمي إلى شخصية البطل المغامر ويتأثر به ويقلده فتكون تلك الثخصية هي الملهمة للطفل المتلقي و أنموذجه الأعلى، لذلك يجب اختيار الشخصيات الإيجابية في محيطها لكي تنقل الإيجابية للطفل ويذو حذوها.

$$
\text { مصادر العمل الارامي والمسرح المدرسي: }
$$

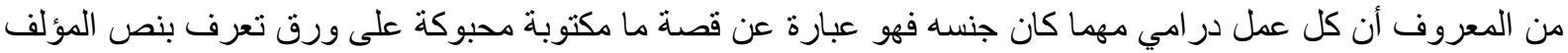

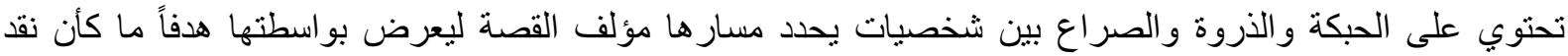

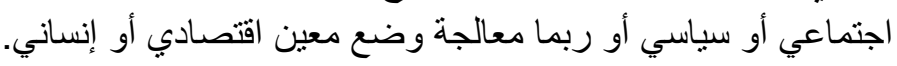


أما المسرح المدرسي في الغالب لا يعتمد على قصة سردية بل يعتمد المناهج الدراسية للطالب في محيط صفه ومدرسته الزها

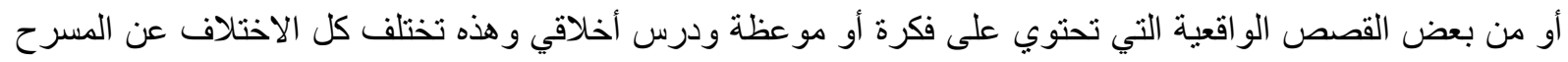

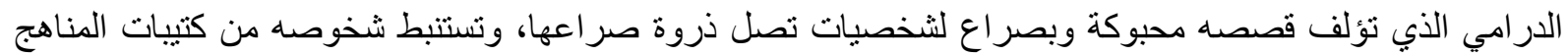

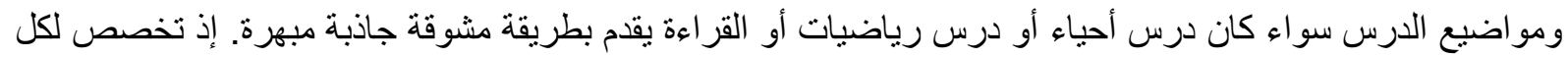

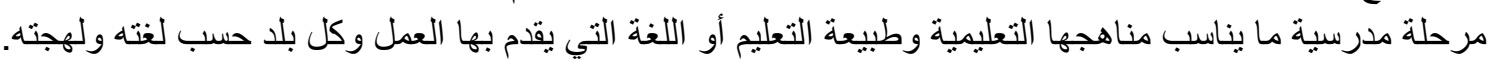

\section{تقنيات المكياج والاضافات الجمالية:}

إن نصوص المسرح لا تكتب للقراءة حسب بل ان هذا النوع من الفن لا يكتمل ابداعه الا إذا بلغ الخشبة بعملية التحويل

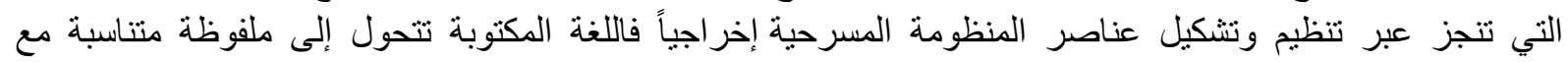

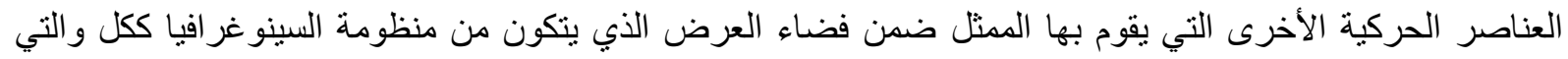
هي فن تتسيق الفضاء، والتحكم في شكله بغرض تحقيق أهداف العرض المسرحي (...) الذي بشكل إطاره الذي تجري الذئي فيه الأحداث.

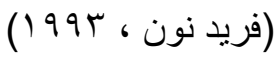

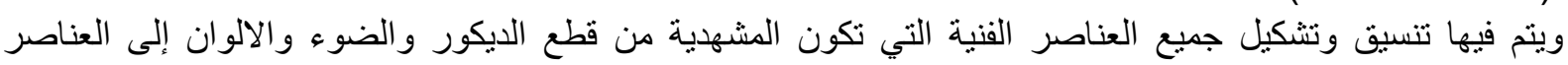
الاخرى كالأزياء و الماكياج و الملحقات المنات الأخرى. ان هذه العناصر تتمظهر في الصورة الإياه والتجسيدية للعرض المسرحي الذئي ينكون من مشاهد ولوحات سمعية وبصرية تنقله

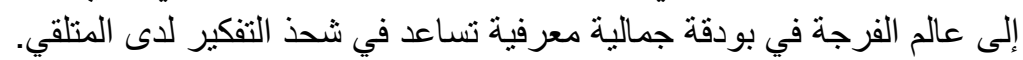

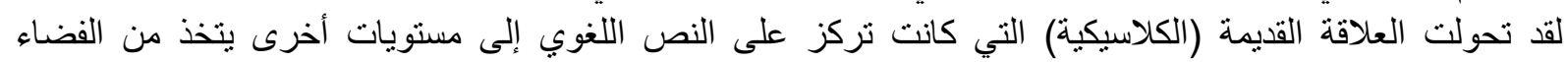

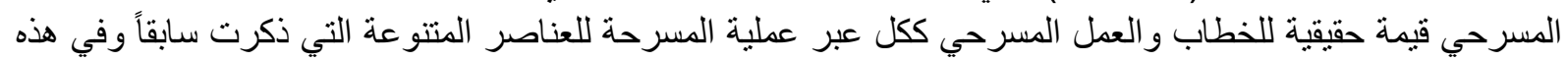

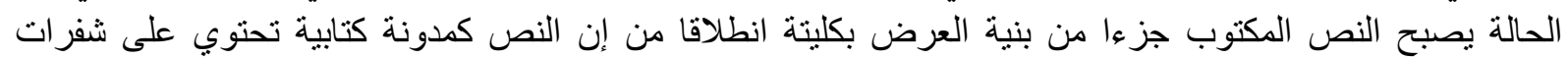

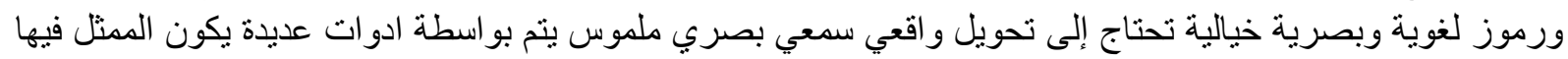

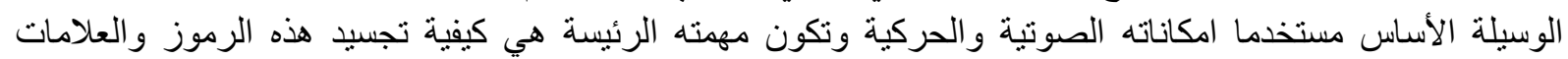

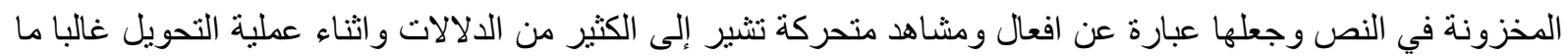

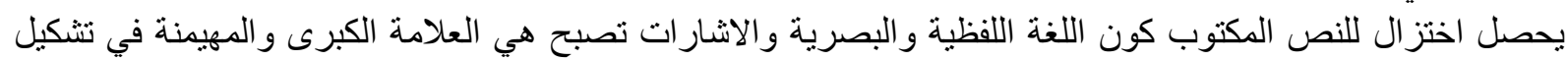

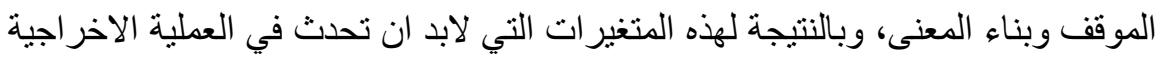

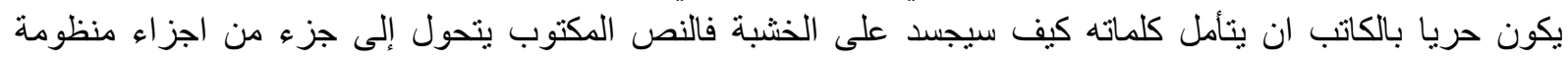

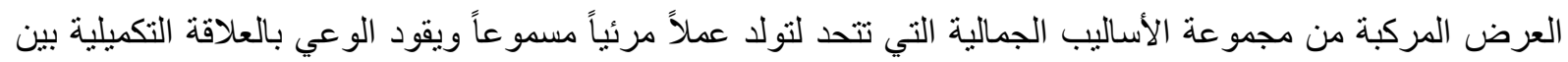

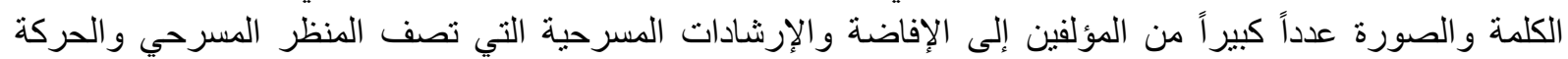

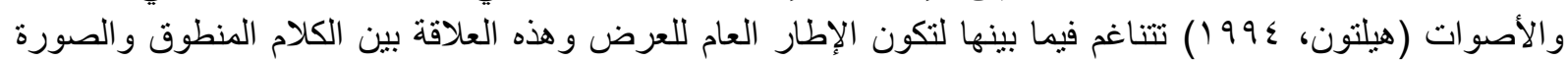

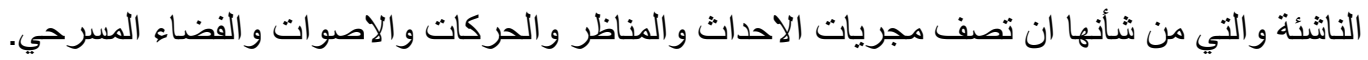

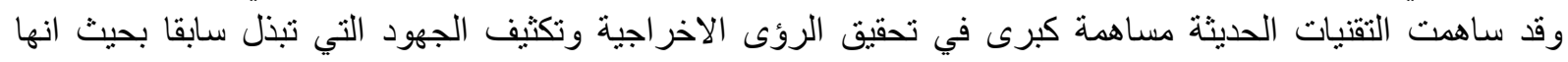

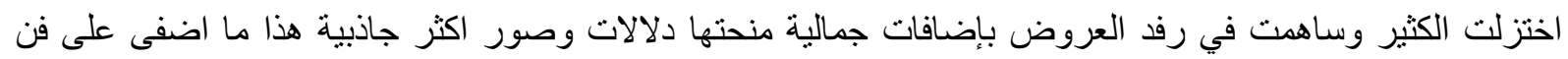

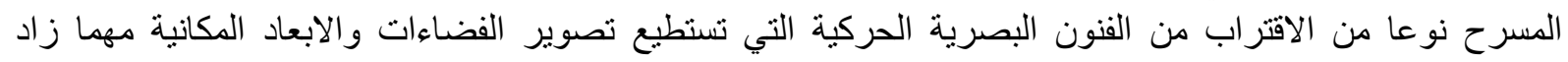

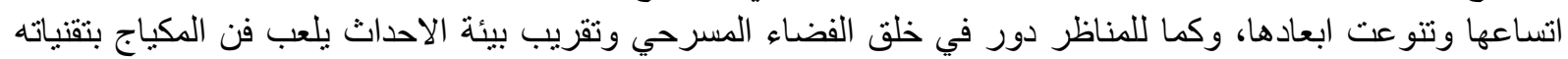

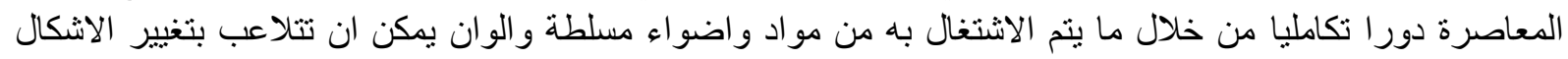

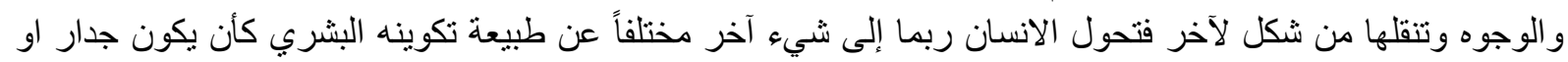

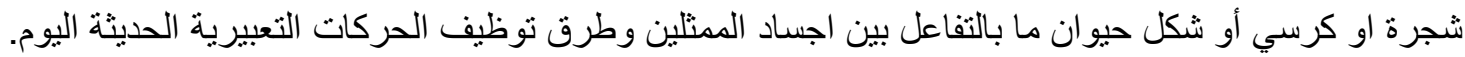

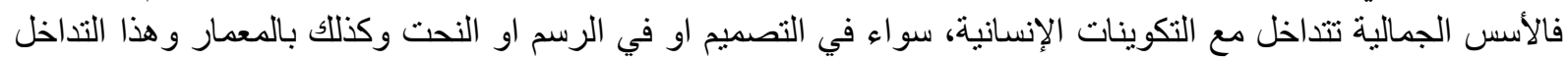

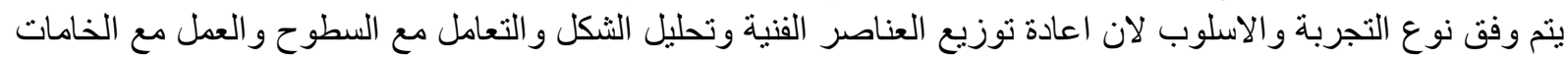

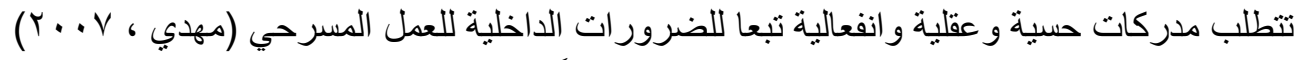

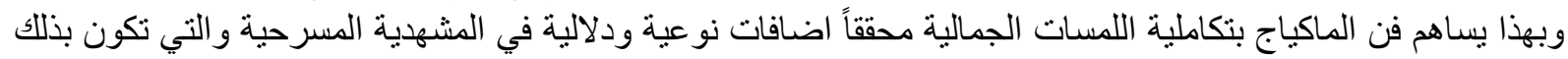
كله فرجة فنية جذابه تتو افر على المضامين الفكرية والاشكال الفنية الجمالية محققة الاثر وفعل التلقي الإيجابي. 
من خلال ما تقدم توصلت الباحثة إلى النتائج وكما يأتي:

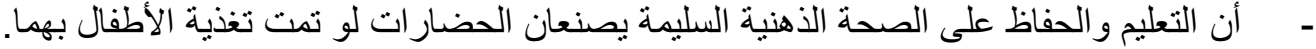

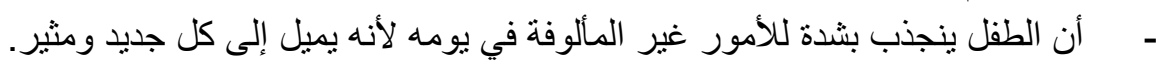

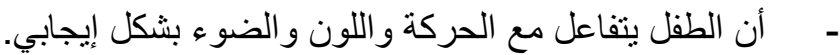

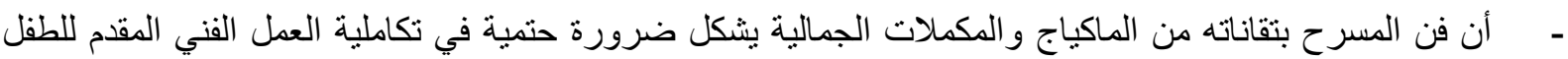
المتلقي.

- - - إن المنهج المدرسي يكون أكثر فهماً وفائدة عندما يتحول إلى فعل درامي ممسرح بطريقة علمية وجمالية - - أن الطفل يتفاعل بحب مع شخصيات معينة يحبها ويجعلها رمزه المثالي يحاكيها ويقوم بتقليدها.

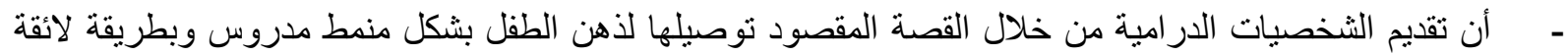
دون إسفاف يساعد في زيادة التركيز على الدرس.

\section{التوصيـات: توصي الباحثة بما يأتي}

أن يربى الطفل تربية فنية جمالية لتحفيز قدر اته الإبداعية * التركيز على طرق التفكير الايجابي و التعبير السليم

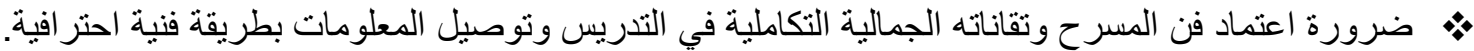

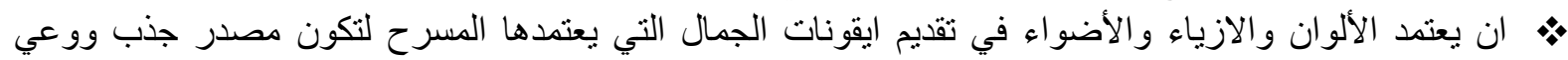
و وابهار للطفل.

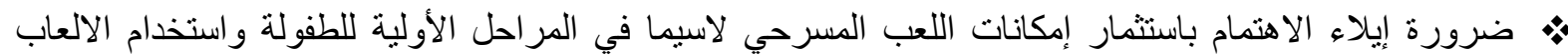

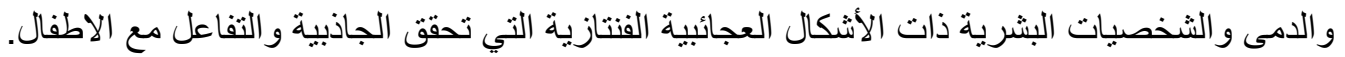

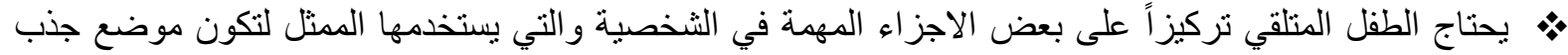
وتو اصل. • ثعليم الطفل التركيز والانتباه والتعبير أول شيء ثم ترسيخ في ذهنه المادة الدراسية بغية مساعدتهم على تقبل الموضوع المطروح. •. أما الأطفال غير الطبيعيين في تكوينهم العقلي أو النفسي فهو مرشد وطبيب سايكولوجي لهم بما يعرف بالمسرح السايكولوجي أو السايكودر امي.

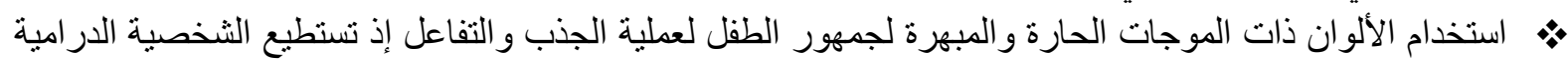
إيصال الفكرة المنشودة تربويا وفنياً إضافة إلى خلق خيال واسع وتعريفه بالاستخدامات التقات التنية الجديدة.

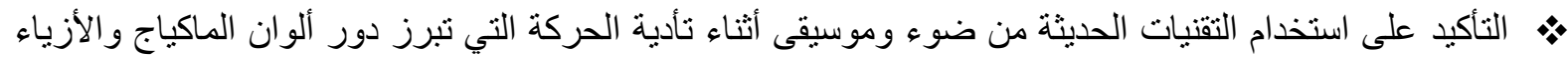

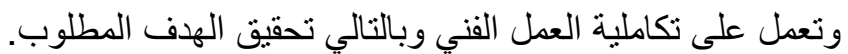
• الاهتمام بدراسة تقنية الماكياج لتطوير وتثجيع العمل علها لآنها حرفة وتقنية عالية التكثيف الدلالي على خشبة المسرح إضافة لجمالياتها واختيار المصممين المحترفين فئها.

إن للتقانات الحديثة دور مهم في حياتتا بكل تفاصيلها إذ أسست الثورة الصناعية لإنسان واعي ذا تفكير قويم و أساس سليم

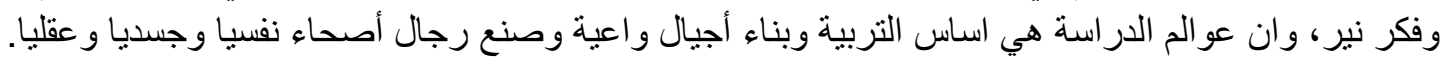
اصبحت ضرورة توفير التعلم بطرق مبسطة مسلية تعمها أجواء التسلية والتعويض ولما ولئ يمكن ان يلعبه المسرح من دور

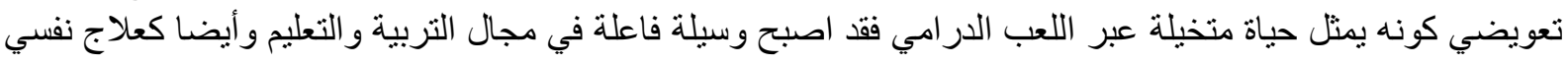
لبعض الفئات التي تشعر بالعوز الجسدي والـئ الذهني.

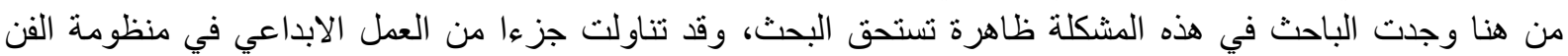
المسرحي وهو فن المكياج. 


\section{تحليـلـل العينــة \\ اسم المسرحية: الرسام الموهوب}

تحكى المسرحية عن موهبة الطفل شادي في فن الرسم حينما يحلم بوجوده على كوكب المشترى ويقوم برسم طفل من

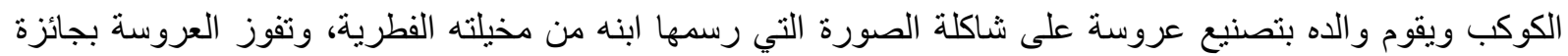

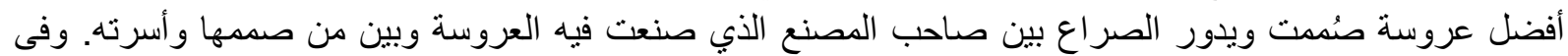
العرض تتداخل العوالم وتتعايش مع بعضها فنحن أمام ممثلين بشر بكامل حلتهم المسرحية ومكياجهم، وعر ائس وهذا

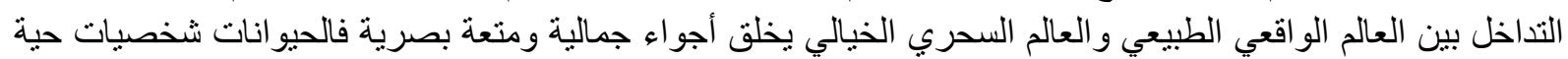

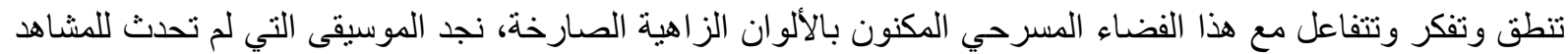

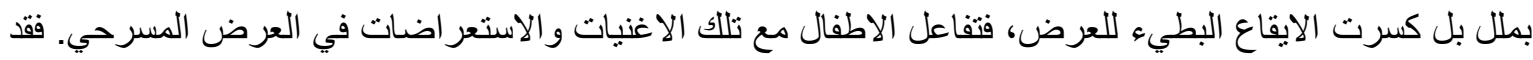

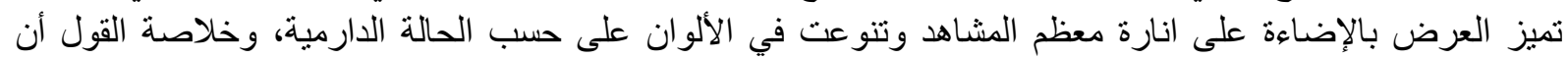

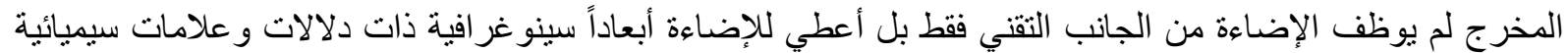

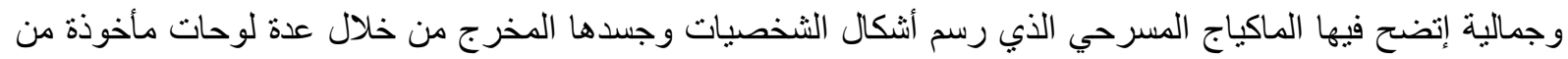
بعض حكايات وقصص كليلة ودمنة ومأخوذة من مسرحية يحكيها الأر اكوز بعد تحضيرات وتمات المارين وبعد قراء اءتات عديدة

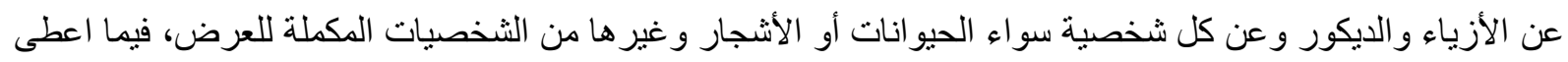

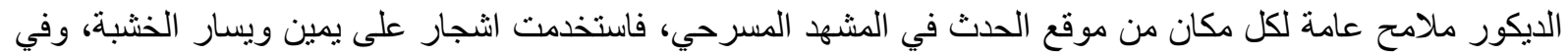

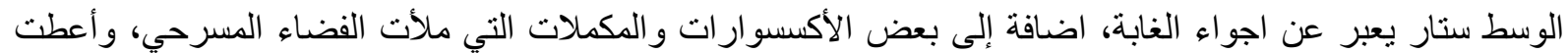

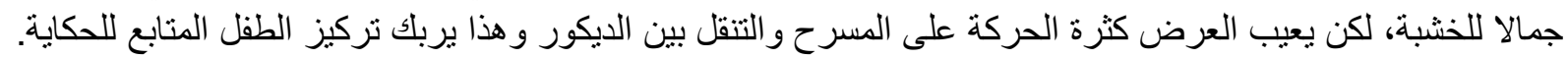

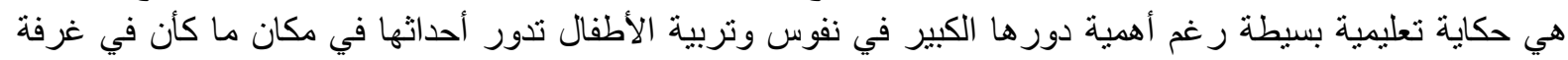

الصف.

المصادر

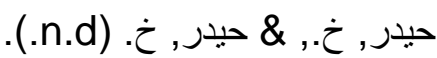

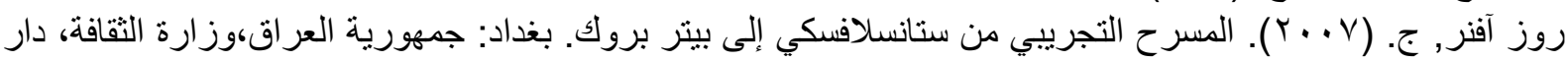

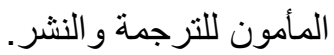

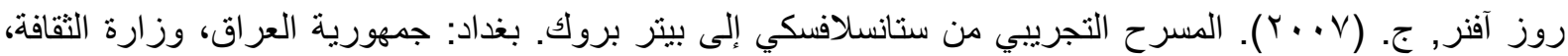

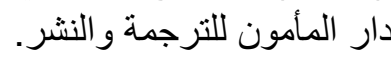

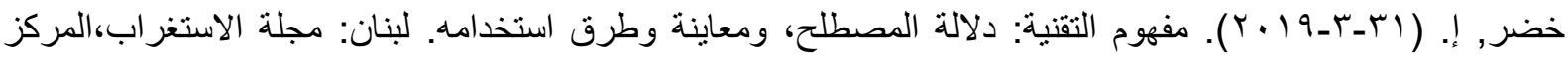
الاسلامي للار اسات الاستر اتيجية.

عبادي, ذ. (2021). ضعف توظيف التقنيات الحديثة دلالياً وجمالياً في مشهدية العروض المسرحية- تقنية الماكياج

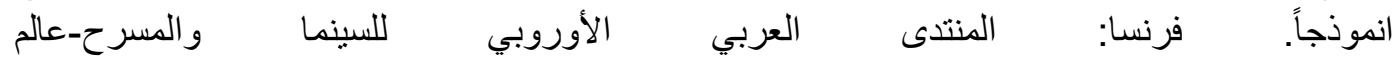

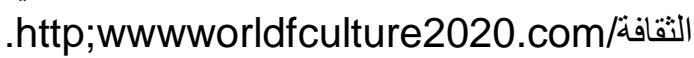

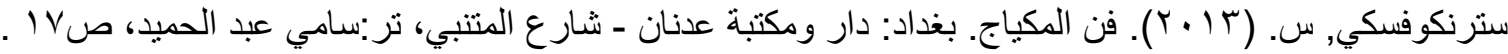

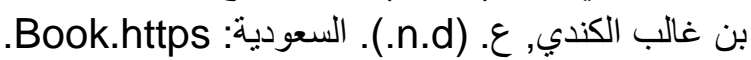

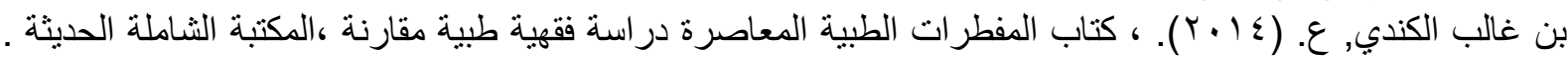

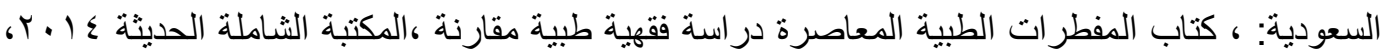

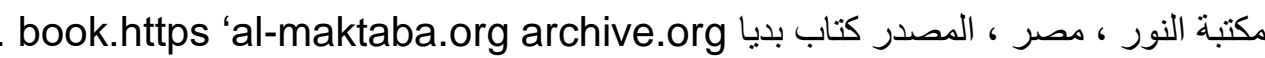
ابن فارس بن زكريا, أ. (395هـ). مقاييس اللغة، ج4. مصر: 'https;//archive.org.

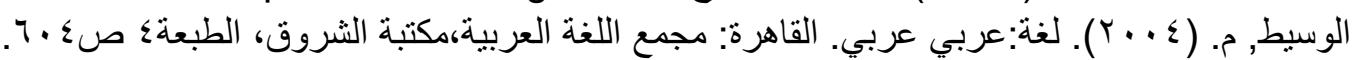

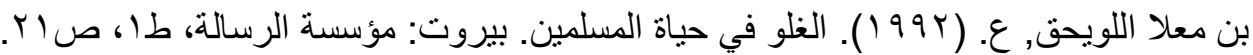

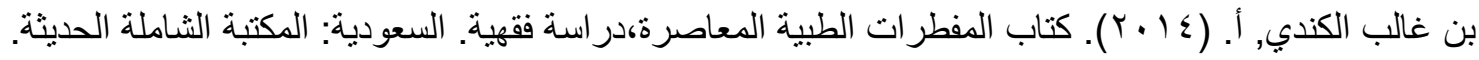

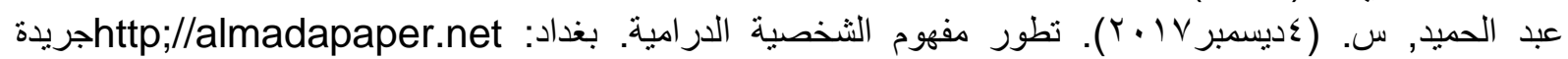

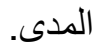


وارد, و. (917 (1) ). مسرح الأطفال. بغداد: وزارة التعليم العالي ، المطبعة العصرية. viola, a. (1974). children's theatre and creative Dramatics. Britain: clarification of .tersel

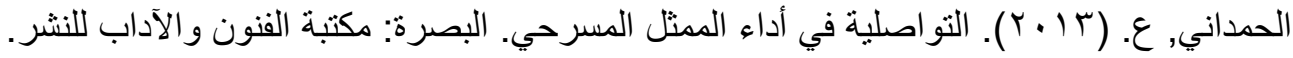

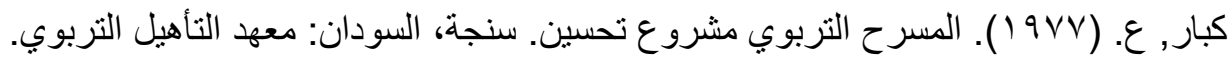

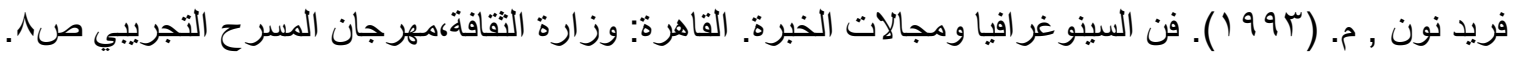

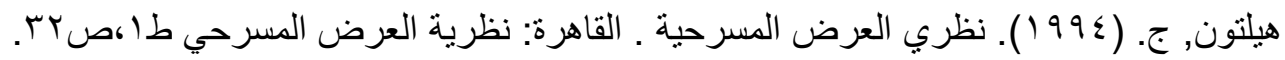

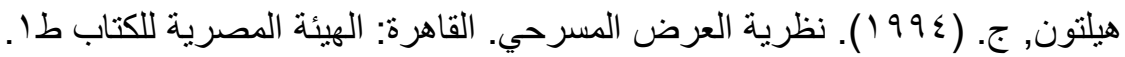

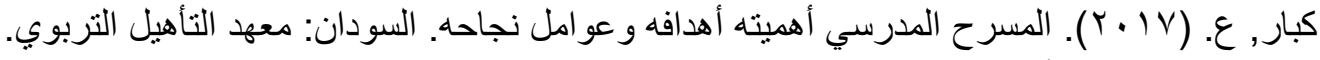

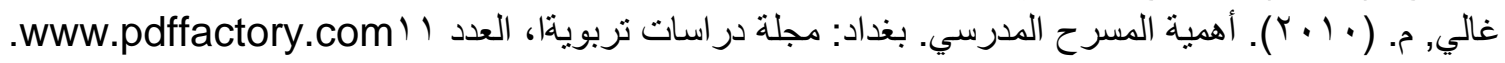

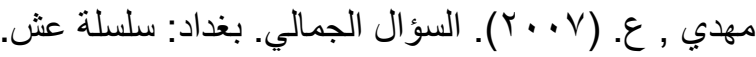

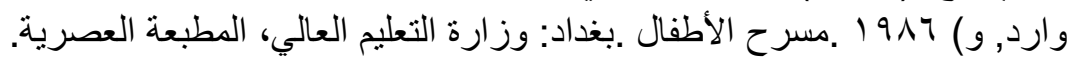
viola, a. (1974). children's theatre and creative Dramatics. Britain: clarification of tersel.

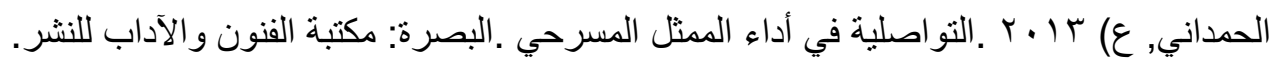

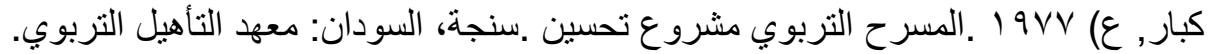

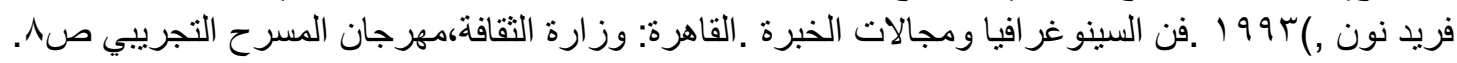

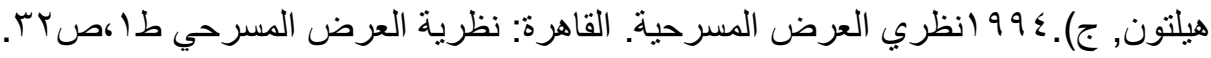

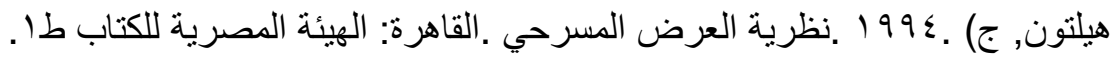

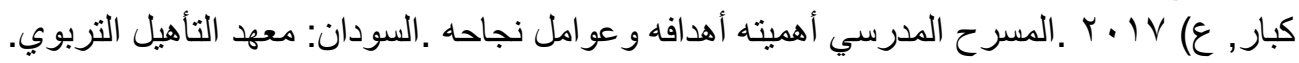

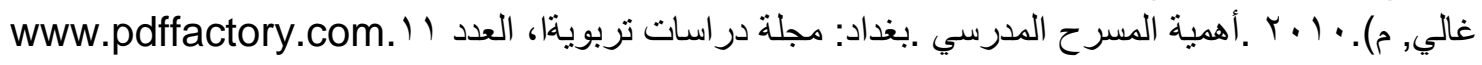

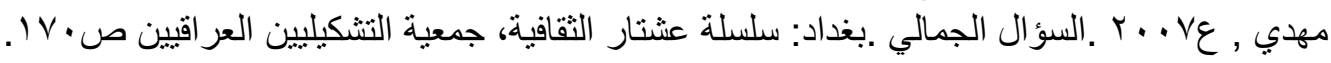

